\title{
On the Form Drag Coefficient Under Ridged Ice : Laboratory Experiments and Numerical Simulations From Ideal Scaling to Deep Water
}

$\mathrm{Zu}, \mathrm{Y}$.

2021-08

Zu , Y , Lu , P , Leppäranta , M , Cheng , B \& Li , Z 2021 , ' On the Form Drag Coefficient Under Ridged Ice : Laboratory Experiments and Numerical Simulations From Ideal Scaling to Deep Water ' , Journal of Geophysical Research : Oceans , vol. 126 , no. 8 , ARTN e2020JC016976 . https://doi.org/10.1029/2020JC016976

http://hdl.handle.net/10138/337728

https://doi.org/10.1029/2020JC016976

acceptedVersion

Downloaded from Helda, University of Helsinki institutional repository.

This is an electronic reprint of the original article.

This reprint may differ from the original in pagination and typographic detail.

Please cite the original version. 
1 On the form drag coefficient under ridged ice: Laboratory experiments and numerical simulations from ideal scaling to deep water

$4 \quad{ }^{1}$ State Key Laboratory of Coastal and Offshore Engineering, Dalian University of

Technology, Dalian, China.

${ }^{2}$ Institute of Atmosphere and Earth Sciences, University of Helsinki, Helsinki, Finland.

${ }^{3}$ Finnish Meteorological Institute, Helsinki, Finland.

Corresponding author: Peng Lu (lupeng@dlut.edu.cn)

\section{Key Points:}

- The local form drag coefficient $C_{\mathrm{dw}}$ under ridged ice is parameterized by both laboratory experiments and numerical simulations.

- In laboratory experiments with finite water depth, $C_{\mathrm{dw}}$ was found to be sensitive to the ridge keel depth and slope angle.

- A logarithmic function of keel slope angle is proposed for deep water $C_{\mathrm{dw}}$ applicable in sea-ice dynamic models. 


\section{Abstract}

The bottom topography of ridged sea ice differs greatly from that of other sea-ice types. The form drag of ridge keels has an important influence on sea-ice drift and deformation. In this study, both laboratory experiment (LabE) and fluid dynamics numerical simulation (FDS) have been carried out for a physical ridge model in a tank to better understand the quantitative characteristics of the form drag. The LabEs covered both laminar and turbulent conditions. The local form drag coefficient of a keel, $C_{\mathrm{dw}}$, varied with the keel depth $h_{\mathrm{w}}$ and the slope angle $\alpha_{\mathrm{w}}$ in the turbulent regime. After validated by the LabE measurements, the FDSs were employed to extend the parameterization from the finite water depth to deep water. The results gave $C_{\mathrm{dw}}=$ $0.68 \cdot \ln \left(\alpha_{\mathrm{w}} / 7.8^{\circ}\right), R^{2}=0.998,10^{\circ} \leq \alpha_{\mathrm{w}} \leq 90^{\circ}$, with $C_{\mathrm{dw}}$ ranging from 0.17 to 1.72 , when the keel depth was much less than the water depth. For a large ridging intensity (keel depth/spacing $\geq 0.01$ ), the variation of the local form drag coefficient and its contribution to total drag coefficient were sensitive to the keel slope angle. Assuming the log-normal distribution for this angle, the average value of the local form drag coefficient was 0.75 , recommended for sea-ice dynamic models.

\section{Plain Language Summary}

Sea ice floats in the polar oceans. Wind and ocean currents generate drag forces for sea ice to drift. The form drag force, also known as the pressure drag force, on sea ice is closely associated with the shape and size of ice floes and ridges. Ridged sea ice has the most irregular geometry of all ice types of ice floes. The predicted thinning of Arctic 
sea ice would lead to more easy deformation of ice floes, resulting in more abundant sea-ice ridge formation and enhancing the form drag forces on sea ice. The form drag coefficient needs to be accounted for in sea-ice models. The local form drag coefficient of ridges was investigated in this study by tank experiments and numerical simulations with an idealized ice ridge model. Based on the results, a logarithmic function was chosen to describe the relationship between the local form drag coefficient and the keel slope angle in deep water conditions. The new parameterization of the local form drag coefficient can be applied in sea-ice models.

\section{Introduction}

Arctic sea ice cover has been changing rapidly with global warming in the past several decades (Screen and Simmonds, 2010; Onarheim et al., 2018; Notz and Stroeve, 2018). Arctic sea ice is not only shrinking in extent, but also in thickness (Rothrock et al., 1999; Comiso, 2012; Stroeve et al., 2012). The exchange of momentum between the atmosphere and the ocean is modified with the decline in Arctic sea ice (Martin et al., 2016). A thinner ice cover is more easily broken under the actions of ocean waves and wind stress (Castellani et al., 2014; Petty et al., 2017). Consequently, the drift speed of Arctic pack ice has increased significantly, although the wind force has remained the same (Rampal et al., 2009; Spreen et al., 2011). In regions exposed to storm events, the sea-ice distribution can change quickly, with the drift speed having reached even $1 \mathrm{~m} / \mathrm{s}$ (Itkin et al., 2017). Thinner sea ice is more easily subject to deformation, resulting in sea-ice ridging or hummocking (Leppäranta, 2011). The drift patterns of ridged ice and 
level ice differ considerably because of the complex topography of ridges, with a sail on top and a keel at the bottom.

The atmospheric and oceanic drag forces on sea ice depend on the ice surface, bottom roughness, and boundary-layer flows. Early methods of calculating these momentum fluxes mostly regarded the drag coefficients as constants in non-stratified boundary layers. Later on, based on the Monin-Obukhov and Rossby similarity theories (Blackadar and Tennekes, 1968; Obukhov, 1971; Banke et al., 1980), the revised drag coefficients depended on the stability of the boundary-layers and the roughness length of the sea-ice surface and bottom. The turbulent flow regime was the main consideration in earlier studies (Overland, 1985; McPhee, 2012).

The drag force consists of the tangential shear stress or skin friction and the form drag, which takes the drag force component normal to large roughness elements, i.e., floe edges and ridges (Mai et al., 1996; Garbrecht et al., 2002; Lüpkes et al., 2012). With the decline of multiyear ice in the Arctic Ocean, a thinner ice cover is more easily broken, and the variations in the surface topography are higher than previously (Castellani et al., 2014). Both the air-ice and ice-ocean drag coefficients, $C_{\mathrm{a}}$ and $C_{\mathrm{w}}$, reach their maxima in the summer during their annual cycle, and the contributions from the form drag are significant because the floe size and ridge spacing are reduced more dramatically than the ice thickness during the melt season (Leppäranta et al., 1995; Tsamados et al., 2014). 
The drag force exerted on ice ridges obeys a quadratic drag law (Arya, 1973), associated with wind and current velocity and the local form drag coefficients of individual obstacles, denoted by $C_{\mathrm{dw}}$ for a keel and $C_{\mathrm{da}}$ for a sail, where the subscripts $\mathrm{W}$ and a represent the ice-ocean and air-ice interface, respectively. With the increasing spatial resolution of numerical sea-ice dynamic models, different types of ice have been included in sea-ice dynamic models that reflect the ice thickness distribution, especially the ridged ice contribution. The scheme by Arya is widely used in present models, for instance, the Helsinki multicategory sea ice model (HELMI) (Haapala et al., 2005; Mårtensson et al., 2012) and the Los Alamos sea-ice model (CICE) (Hunke et al., 2013; Tsamados et al., 2014; Martin et al., 2016). The results of the CICE model by Martin et al. (2016) showed that the form drag on ice ridges contributed to more than half of the total drag in the winter seasons from 1980 to 2010. drag forces. Banke and Smith (1975) obtained $C_{\text {da }}$ proportional to the sail height $h_{\mathrm{a}}$ and 93 the sail slope $\alpha_{\mathrm{a}}$. Garbrecht et al. (1999) continued to summarize a logarithmic approach

94 for the dependence of $C_{\mathrm{da}}$ on $h_{\mathrm{a}}$ based on the measurements of wind profiles on the 95 leeward side of a pressure ridge. Drag force studies have been mostly conducted in the 96 atmospheric boundary layer (ABL) over sea ice, and only a few cases have been 97 reported for ridge keels in the oceanic boundary layer (OBL). This is mainly because 98 field measurements are more difficult in underwater operations in the OBL than on the 99 ice surface. Laboratory experiments provide an effective way to investigate the 
interaction between ice and water by directly measuring the drag force and altering the

101 test parameters. For example, Pite et al. (1995) have investigted the drag force on the

102 keel model by laboratory measurements. However, the depth of the turbulent boundary

103 layer is limited by the fixed tank bottom in laboratory experiments. In deep,

104 homogeneous water, the depth of the turbulent boundary-layer is an order of magnitude

105 greater than the depth of keels.

This study is a continuation of the ice-ocean drag coefficient study by Lu et al.

107 (2011). Here, we focus on the parameterization of the local form drag coefficient

108 between ridged ice and ocean. This manuscript is organized as follows: Section 2

109 provides a theoretical parameterization of the ice-ocean drag coefficient based on Lu et

110 al. (2011) followed by and the motivations of this study. In Section 3, two methods i.e.

111 laboratory experiment (LabE) and fluid dynamics numerical simulation (FDS) used in

112 this study are described. The results for the local form drag coefficient $C_{\mathrm{dw}}$ for a keel

113 identified by both LabE and FDS are presented in Sections 4.1 and 4.2. Then FDSs are

114 extended from finite depth water to deep water, and a parametrization scheme of $C_{\mathrm{dw}}$ is

115 presented in Section 4.3. Applications of $C_{\mathrm{dw}}$ for a geometry-based ice-ocean drag

116 coefficient and the results on the spatial distribution of keel angle are discussed in

117 Section 5. Finally, conclusions are drawn in Section 6.

\section{Parameterization of the Ice-ocean Drag Coefficient}

119 Ice-ocean stress $\tau_{\mathrm{w}}$ is commonly expressed by the quadratic bulk formula, in

120 complex form as 


$$
\tau_{w}=\rho_{w} C_{w}\left|U-U_{w g}\right|\left(\cos \theta_{w}+i \sin \theta_{w}\right)\left(U-U_{w g}\right)
$$

122 where $\rho_{\mathrm{w}}$ is the water density, $C_{\mathrm{w}}$ is the ice-ocean drag coefficient, $U$ is the ice velocity,

$123 U_{\mathrm{wg}}$ is the geostrophic flow beneath the Ekman layer, and $\theta_{\mathrm{w}}$ is the boundary-layer

124 turning angle or the Ekman angle. According to the drag partition theory, ice-ocean

125 stress can be divided into two parts: the skin friction due to the surface shear stress, and

126 the form drag on floe edges and ice ridges due to the lateral pressure difference across

127 the obstacles (Arya, 1975). Further observations and model studies have shown that

128 both ice-ocean and air-ice drag coefficients are related to ice concentration, floe size,

129 keel and sail and other geometry parameters (Hassen-Bauer and Gjessing, 1988; Steele

130 et al., 1989; Garbrecht et al., 2002; McPhee, 2002; Lüpkes and Birnbaum, 2005).

131 According to Eq. (1) and the drag partition theory, the geometry-based

132 parametrizations of the drag coefficients have been proposed by Lu et al. (2011) and

133 Tsamados et al. (2014), which are hereafter referred to as LU2011 and TS2014.

134 LU2011 used the ice velocity relative to a fixed background geostrophic velocity $U_{\mathrm{wg}}$,

135 which is different from the reference velocity at a specific depth used in TS2014. Due

136 to the different reference depths, a conversion factor $C_{\mathrm{h}}$ is needed to compare the keel

137 drag coefficients between the two schemes. The details are introduced in the Supporting

138 information of Text S1.

140 sea-ice geometry, including sea-ice concentration, floe size, and ridging intensity, 141 particularly in heavily ridged regions (e.g., offshore areas) and low ice concentration 
142 regions (e.g., a marginal ice zone) (Martin et al., 2016; Brenner et al., 2020). As

143 described by Lu et al. (2011), $C_{\mathrm{w}}$ can be calculated as follows:

$$
\begin{gathered}
C_{w}=C_{E w}+C_{R w}+C_{S w}=f_{1} C_{e w}+f_{2} C_{d w}+f_{3} C_{s w} \\
f_{1}=\frac{A d_{w}}{2 L_{f}}\left[1-\left(\frac{A}{1-A} \frac{d_{w}}{L_{f}}\right)^{1 / 2}\right]^{2} \\
f_{2}=\frac{A h_{w}}{\pi L_{r}}\left[1-\left(\frac{h_{w}}{L_{r}}\right)^{1 / 2}\right]^{2} \\
f_{3}=A\left(1-m \frac{h_{w}}{L_{r}}\right)
\end{gathered}
$$

148 where $C_{\mathrm{Ew}}, C_{\mathrm{Rw}}$, and $C_{\mathrm{Sw}}$ represent the drag coefficients that contribute, respectively, to

149 the form drag by floe edges, form drag on ice keels, and the skin friction on the ice

150 surface. $C_{\mathrm{ew}}, C_{\mathrm{dw}}$, and $C_{\mathrm{sw}}$ are the local drag coefficients for the contributions of a single

151 floe edge, a single ice ridge, and uniform ice surface, respectively. $A$ is ice

152 concentration, $d_{\mathrm{w}} / L_{f}$ is the ratio of floe draft to floe length, and $h_{\mathrm{w}} / L_{r}$ is the ridging

153 intensity or the ratio of keel depth to keel spacing. The terms in the brackets for the

154 functions $f_{1}$ and $f_{2}$ account for the shielding effects, and the factors in front of the

155 brackets account for the vertical dimension of the drafts and adding up the drag spatially

156 for a grid cell. $f_{3}$ is the roughness friction function, where $m$ is a constant equal to 10 in

157 the OBL (Lu et al., 2011). over a wide range. It was measured as $0.51-0.62$ in the laboratory experiment by Pite et al. (1995). In the calculation of the CICE model by TS2014 formulation, $C_{\mathrm{dw}}$ is set 
162 conversion factor of 0.76 to compare with this study, for the details see Supporting

163 information Text S1). In LU2011, $C_{\mathrm{dw}}$ was used as a constant equal to 0.5 in the 164 sensitivity experiments. coefficient $C_{\mathrm{Rw}}$. Since ridge keels in Arctic seas have a more complicated morphology than floe edges (Bitz et al., 2001; Obert and Brown, 2011; Wadhams et al., 2011), $C_{\mathrm{dw}}$ has a range of values corresponding to various keel shapes rather than being a constant. Using the simple triangular shape of ridge keel (Ekeberg et al., 2015; Bonath et al., 2018; Kharitonov et al., 2020), the slope angle $\alpha_{\mathrm{w}}$ and the keel depth $h_{\mathrm{w}}$ define the keel

171 geometry. The goal of this study is to investigate how $C_{\mathrm{dw}}$ varies with the keel geometry,

172 and a parameterization scheme of $C_{\mathrm{dw}}=C_{\mathrm{dw}}\left(\alpha_{\mathrm{w}}, h_{\mathrm{w}}\right)$ with its range of variation is 173 presented, allowing an improved formulation of the ice-ocean drag coefficient in Eq.(2). The LabEs were performed in a rectangular water tank, which was $0.23 \mathrm{~m}$ wide,

$1774.5 \mathrm{~m}$ long, and $0.45 \mathrm{~m}$ deep, with glass panels fitted on the sides and the bottom, as

178 shown in Fig. 1a. The ridge keel model was designed to be a wedge-shaped symmetric

179 element using Perspex materials. When the keel model was driven along the water 180 surface, the drag force on the ridge keel exerted by water was recorded. The force sensor 181 was fixed between the motor and the keel model to measure the drag force in the 
182 horizontal direction. The sensor range was $10 \mathrm{~N}$, the accuracy was $0.001 \%$, and the

183 sampling frequency was $50 \mathrm{~Hz}$. The experimental setup is shown in Fig. $1 \mathrm{~b}$.

184 Previous observations have shown that sea-ice ridges in the Arctic Ocean have

185 a triangular sail, while their keel is triangular in first-year (FY) ridges and trapezoidal

186 in multiyear (MY) ridges (Timco and Burden, 1997; Strub-Klein and Sudom, 2012).

187 The present study focuses on the FY ice because of its increasing seasonality and

188 prevalence in the Arctic Ocean nowadays (Kwok et al., 2009; Onarheim et al., 2018;

189 Bi et al., 2020). For a triangular keel moving in a homogenous fluid, an earlier

190 dimensional analysis showed that the keel drag coefficient $C_{\mathrm{dw}}$ can be expressed as

$191 C_{\mathrm{dw}}=f\left(\operatorname{Re}, D / h_{\mathrm{w}}, \alpha_{\mathrm{w}}\right)\left(\mathrm{Zu}\right.$ et al., 2020), where $R e$ is the Reynolds number, $D / h_{\mathrm{w}}$ is the

192 ratio of water depth to keel depth, and $\alpha_{\mathrm{w}}$ is the keel slope angle. The keel depth $h_{\mathrm{w}}$ and

193 the slope angle $\alpha_{\mathrm{w}}$ are the two control parameters of the keel model. Table 1 lists the

194 observed keel depth and the slope angle in real conditions. Normally keel slope angles

195 are within $20^{\circ}-30^{\circ}$, but the maximum can be as high as $87.5^{\circ}$. The keel depth varies

196 in a large range and acts as a factor of turbulence generation in the boundary-layer under

197 the ice.

The LabEs covered the laminar and turbulent flow regimes and the transition

199 regime between them. For different keel shapes, the transition flow regime was related

200 to the Reynolds number, which reflects the flow pattern (Schlichting and Gersten, 201 2017):

$$
R e=\frac{U L_{w}}{v}
$$


203 where $L_{\mathrm{w}}=2 h_{\mathrm{w}} / \sin \left(\alpha_{\mathrm{w}}\right)$ is the keel wet length, and $v=1.003 \times 10^{-6} \mathrm{~m}^{2} / \mathrm{s}$ is the kinematic

204 viscosity coefficient of water viscosity.

205

Table 1. Ridge keel parameters of Arctic FY ice

\begin{tabular}{|c|c|c|c|c|}
\hline Region & Slope angle $/{ }^{\circ}$ & Keel depth/m & Reynolds number & References \\
\hline $\begin{array}{l}\text { Beaufort Sea } \\
\text { and Central } \\
\text { Arctic Ocean }\end{array}$ & 26.6 (Mean) & - & - & $\begin{array}{c}\text { Timco and } \\
\text { Burden, } \\
1997\end{array}$ \\
\hline $\begin{array}{c}\text { East Coast } \\
\text { Canada }\end{array}$ & 24.92 (Mean) & 2.94 (Mean) & $1.4 \times\left(10^{5}-10^{7}\right)$ & $\begin{array}{l}\text { Obert and } \\
\text { Brown, } \\
2011\end{array}$ \\
\hline Fram Strait & $15-24$ & $5.1-6.7$ & $2.5 \times 10^{5}-5.2 \times 10^{7}$ & $\begin{array}{c}\text { Sand et al., } \\
2015\end{array}$ \\
\hline Barents Sea & $8-29$ & $3.4-7.6$ & $1.4 \times 10^{5}-1.1 \times 10^{8}$ & $\begin{array}{c}\text { Sand et al., } \\
2015\end{array}$ \\
\hline $\begin{array}{c}\text { Shokalsky } \\
\text { Strait }\end{array}$ & $11.2-87.5$ & $4.36-4.97$ & $8.7 \times 10^{4}-5.1 \times 10^{7}$ & $\begin{array}{c}\text { Kharitonov, } \\
2020\end{array}$ \\
\hline
\end{tabular}

207 Note: The Reynolds number $R e$ is calculated from keel wet length (Eq. 6), where ice

208 velocity $U$ takes on a characteristic value between 0.01 and $1 \mathrm{~m} / \mathrm{s}$ (Thorndike and

209 Colony, 1982; Kreyscher et al., 2000; Leppäranta, 2011; Shu et al., 2012).

$21230^{\circ}, 45^{\circ}$, and $90^{\circ}$. The model in case $\alpha_{\mathrm{w}}=90^{\circ}$ is a $5 \mathrm{~mm}$ thick wall, with the depth one

213 order of magnitude larger than the thickness. This extreme case improved the feasibility

214 of the estimated function $C_{\mathrm{dw}}\left(\alpha_{\mathrm{w}}\right)$ over the entire range of the keel slope. The ratio of

215 water depth to keel depth $D / h_{\mathrm{w}}$ was set into a range of $3.5-8.75$, where the water depth

216 is $D=0.35 \mathrm{~m}$ in the LabEs. The keel model velocity $U$ was set within $0.03-0.3 \mathrm{~m} / \mathrm{s}$, 
217 which included the turbulent flow conditions under the keel model with $R e$ up to $3.4 \times$

$21810^{5}$. The experimental parameters are listed in Table 2.

Table 2. Parameters in LabE and FDS

\begin{tabular}{ccc}
\hline Parameter & LabE & FDS \\
\hline$U$ & $0.03,0.06,0.07,0.08,0.09,0.1$, & $0.06,0.07,0.08,0.09,0.1,0.12$, \\
& $0.12,0.15,0.18,0.24,0.3 \mathrm{~m} / \mathrm{s}$ & $0.15,0.18,0.24,0.3 \mathrm{~m} / \mathrm{s}$ \\
$h_{\mathrm{w}}$ & $0.04,0.06,0.08,0.1 \mathrm{~m}$ & $0.04,0.06,0.08,0.1 \mathrm{~m}$ \\
$\alpha_{\mathrm{w}}$ & $20,30,45,90^{\circ}$ & $10,20,30,45,60,90^{\circ}$ \\
$D$ & $0.35 \mathrm{~m}$ & $0.35,0.7,1.05,1.4 \mathrm{~m}$ \\
$R e$ & $8 \times 10^{2}-1.7 \times 10^{5}$ & $1 \times 10^{4}-3.4 \times 10^{5}$ \\
$D / h_{\mathrm{w}}$ & $3.5-8.75$ & $3.5-35$ \\
\hline
\end{tabular}



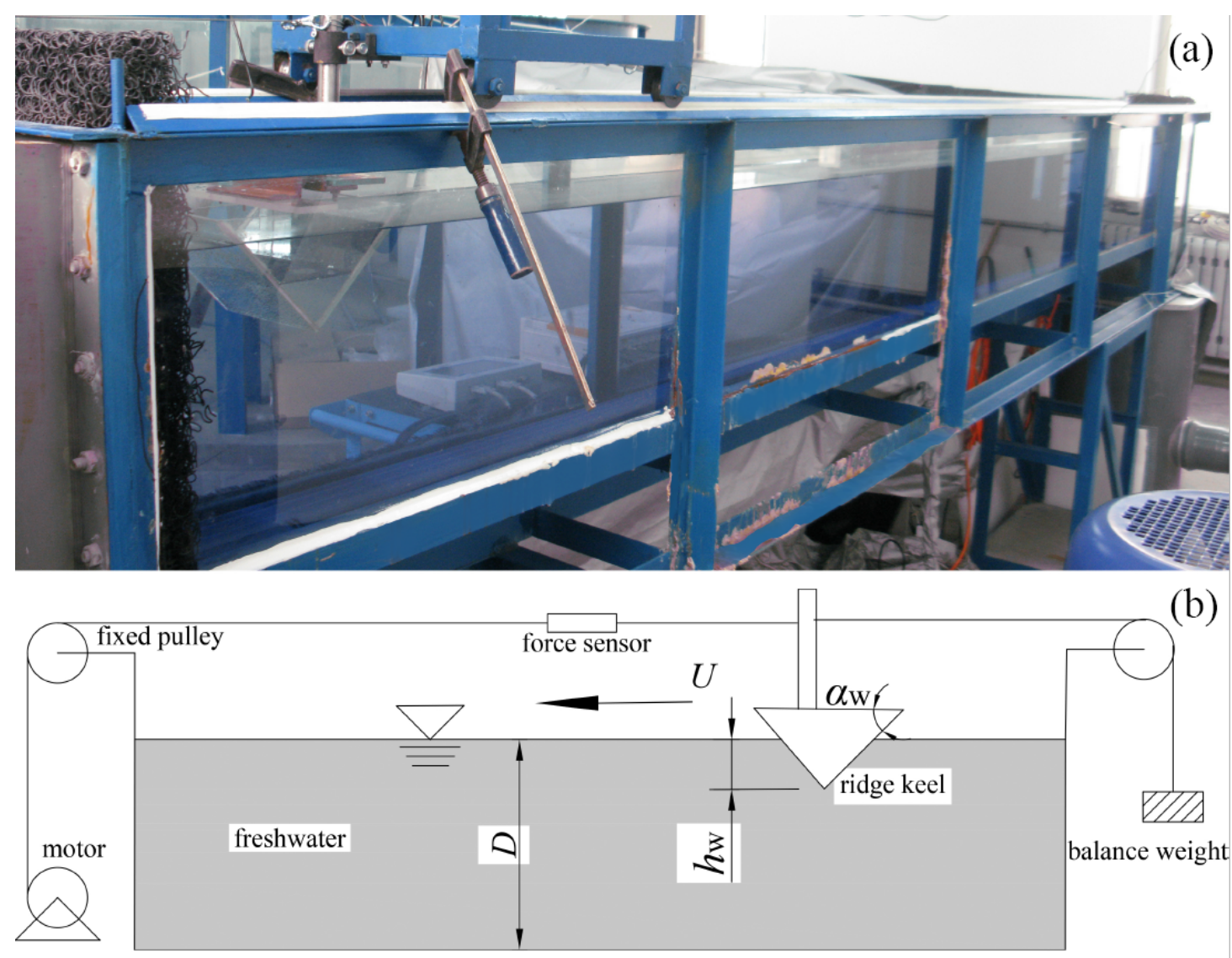

Figure 1. (a) Tank and (b) sketch of LabE setup; $U$ is the keel model velocity simulating ice drift, $h_{\mathrm{w}}$ is the keel depth, and $\alpha_{\mathrm{w}}$ is the keel slope angle.

The FDSs were conducted for $R e>10^{4}$, which represents the turbulent flow

regime. The aim was to compare the simulations with the $\mathbf{L a b E}$ results, and to perform

229 deep water simulations to extend the research outcome, since the laboratory study was

230 limited by the fixed, finite water depth. Provided that hydrodynamic similarity is

231 satisfied, the relative motion of the flow in the FDS tank past the ridge keel at a uniform

232 upstream velocity and the drag force should be the same as in the $\mathbf{L a b E}$, where the keel

233 moves at the same speed in the stationary fluid. 
235 ridge model, the FDS was simplified into a 2-D flow problem. The flow structure here

236 is 2-D rather than 3-D as in the real ocean, and the Coriolis effect is not included. The

237 Coriolis force mainly alters the direction of the drag force but not the absolute value.

238 Details about the Coriolis force are discussed in Supporting information Text S1. The

239 FDS domain was the same as in the laboratory tank, as shown in Fig. 2. Typical cases

240 with a slope angle of $45^{\circ}$ were chosen to test the grid size independence of the

241 simulations. The result stabilized at the grid size between $0.5 \mathrm{~cm}$ and $0.9 \mathrm{~cm}$, and 0.5

$242 \mathrm{~cm}$ was selected as the final grid size. To ensure a fully developed wake flow on the lee

243 side of the keel, the ridge model was placed at one-third downstream in the tank (Fig.

244 2). The distance from the keel to the outlet was 30 times the maximum keel depth.

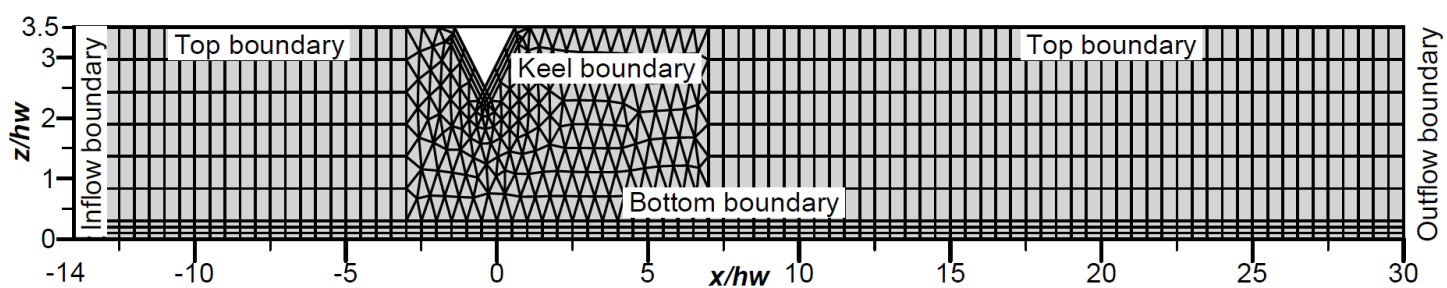

Figure 2. Sketch of the FDS domain. Unstructured grid cells occur near the keel.

The FDSs were based on the $k-\varepsilon$ turbulence model (Launder and Spalding,

250 1972). The momentum equation can be written as:

$$
\frac{\partial u_{i}}{\partial t}+u_{j} \frac{\partial u_{i}}{\partial x_{j}}=-\frac{1}{\rho_{\mathrm{w}}} \frac{\partial p}{\partial x_{i}}+\frac{1}{\rho_{\mathrm{w}}} \frac{\partial}{\partial x_{j}}\left(\mu\left(\frac{\partial u_{i}}{\partial x_{j}}+\frac{\partial u_{j}}{\partial x_{i}}\right)+\tau_{i j}\right)
$$

252 where $u_{\mathrm{i}}$ denotes the velocity components in the Cartesian coordinates $x_{i}, t$ is time, $\rho_{\mathrm{W}}$ 
253 is water density, $p$ is pressure, $\mu$ is the dynamic water viscosity coefficient, and $\tau_{\mathrm{ij}}$ is the

254 Reynolds stress, which is related to the mean velocity gradient according to the 255 Boussinesq hypothesis of an isotropic eddy viscosity $\mu_{\mathrm{t}}$ (Hinze, 1975):

$$
\tau_{i j}=\mu_{t}\left(\frac{\partial u_{i}}{\partial x_{j}}+\frac{\partial u_{j}}{\partial x_{i}}\right)-\frac{2}{3} \rho_{\mathrm{w}} k \delta_{i j}
$$

where $k$ is the turbulent kinetic energy and $\delta_{\mathrm{ij}}$ is the Kronecker delta. The numerical

which was numerically solved by the finite volume method, and the discretization

260 scheme used the second-order upwind method in space and was stable over time. The

261 solver adopted the SIMPLEC algorithm (Liu et al., 2013; Karim et al., 2014). For the

$262 k-\varepsilon$ two equation in renormalization group (RNG) method, $C_{\mu}=0.0845, C_{1 \varepsilon}=1.42, C_{2 \varepsilon}$

$263=1.68$, and $\alpha_{\varepsilon}=\alpha_{\mathrm{k}}=1.39$ (Yakhot and Orszag, 1986; Orszag et al., 1993). Along the

264 keel boundary, Reynolds stresses were zero due to the presence of a viscous sublayer

265 that affected the distribution of the pressure $p$ at the keel boundary. Normal stresses in

266 the flow originated from the pressure $p$ exerted on the keel. The total keel drag was

267 obtained by integrating the frictional and normal stresses along the keel boundary,

268 which lied along the keel bottom boundary $z=\eta(x)$ with given depth $h_{\mathrm{w}}$ and angle $\alpha_{\mathrm{w}}$ :

$$
F=\int_{x=-h_{w} / \tan \alpha_{w}}^{x=h_{w} / \tan \alpha_{w}}\left[\mu\left(\frac{\partial u}{\partial z}+\frac{\partial w}{\partial x}\right) n_{z}+\left(p+2 \mu \frac{\partial u}{\partial x}\right) n_{x}\right]_{z=\eta(x)} d x
$$

270 The fluctuation of the free surface was considered very small and ignored. Furthermore,

271 a no-stress wall was used for the top boundary, where $z=D$ :

$$
w=0, \partial u / \partial z=0, p=0
$$

273 At the bottom $(z=0)$ and at the keel boundary $(z=\eta(x))$, the no-slip boundary conditions 
274 were taken:

$$
u=w=0 .
$$

276 The boundary condition at the velocity inlet and outlet were:

$$
\begin{gathered}
x / h_{\mathrm{w}}=-14: u=U \text { and } w=0, \\
x / h_{\mathrm{w}}=30: \frac{\partial u}{\partial x}=\frac{\partial w}{\partial x}=0 .
\end{gathered}
$$

279 The outlet boundary was far from the flow separation region, and therefore the velocity

280 gradient was zero. The velocity at the outlet was determined by the upstream flow, by

281 continuity, and the streamwise velocity profile was still influenced by the wake effect

282 of the keel topography. To test the influence of the outlet position on the force of the

283 keel, three typical cases with the keel slope of $45^{\circ}$ and the keel depth of $10 \mathrm{~cm}$ were

284 selected. The keel drag force (Table 3) tended to a stable level with increasing $x / h_{\mathrm{w}}$,

285 where $x$ is the horizontal coordinate. For $R e=8.5 \times 10^{4}$, the force decreased slightly 286 with $x / h_{\mathrm{w}}$, but the averaged value with standard deviation was $2.27 \pm 0.05 \mathrm{~N}$, and the 287 values were within $4 \%$. When $x / h_{\mathrm{w}}=30$ was used as the computational domain length, the 288 outlet was then far from the keel to ensure at most a minor effect on the results.

290 Table 3. Tests of the computational domain length $x / h_{\mathrm{w}}$ for the drag force $F(N)$.

\begin{tabular}{cccc}
\hline$x / h_{\mathrm{w}}$ & 30 & 60 & 90 \\
\hline$U=15 \mathrm{~cm} / \mathrm{s}, R e=4.2 \times 10^{4}$ & 0.57 & 0.57 & 0.57 \\
$U=24 \mathrm{~cm} / \mathrm{s}, R e=6.8 \times 10^{4}$ & 1.44 & 1.44 & 1.44 \\
$U=30 \mathrm{~cm} / \mathrm{s}, R e=8.5 \times 10^{4}$ & 2.35 & 2.24 & 2.23 \\
\hline
\end{tabular}


293 condition was imposed on the bottom boundary. Since the bottom boundary-layer was

294 always thin in these experiments, as shown in Fig. 5, no-slip and free-slip conditions

295 made only a little difference in the results. Tests of the no-slip and free-slip conditions

296 were conducted and the results are listed in Table 4.

Table 4. Tests of no-slip and free-slip conditions on the tank bottom.

\begin{tabular}{ccc}
\hline$D / h_{\mathrm{w}}=3.5\left(\alpha_{\mathrm{w}}=45^{\circ}, h_{\mathrm{w}}=10 \mathrm{~cm}\right)$ & No-slip $F(\mathrm{~N})$ & Free-slip $F(\mathrm{~N})$ \\
\hline$U=15 \mathrm{~cm} / \mathrm{s}, R e=4.2 \times 10^{4}$ & 0.57 & 0.56 \\
$U=24 \mathrm{~cm} / \mathrm{s}, R e=6.8 \times 10^{4}$ & 1.44 & 1.45 \\
$U=30 \mathrm{~cm} / \mathrm{s}, R e=8.5 \times 10^{4}$ & 2.35 & 2.21 \\
\hline
\end{tabular}

299

\section{Results}

We shall focus first on the local drag coefficient $C_{\mathrm{dw}}$ of an individual keel and

302 its dependence on the keel depth $h_{\mathrm{w}}$ and slope angle $\alpha_{\mathrm{w}}$ for a finite water depth. Then

303 the results of the two methods are compared and the feasibility of FDS is validated by

304 the LabE measurements. Finally, the FDS is extended to obtain results under deep 305 water conditions $\left(D / h_{\mathrm{w}} \rightarrow \infty\right)$.

308 (Hoerner, 1965; Pite 1995; Schlichting and Gersten, 2017)

$$
F=\frac{1}{2} C_{d w} \rho_{w} h_{w} U^{2}
$$


$311=998.2 \mathrm{~kg} / \mathrm{m}^{3}$. As mentioned in Section 3.1, $C_{\mathrm{dw}}=f\left(R e, D / h_{\mathrm{w}}, \alpha_{\mathrm{w}}\right)$. Figs. 3a-d show that

$312 C_{\mathrm{dw}}$ varies with $R e$ at different $D / h_{\mathrm{w}}$ and $\alpha_{\mathrm{w}}$ (Note that open circles represent FDS

313 results, see details in Section 4.2). According to the ridge parameters and ice velocity

314 characteristics in Table 1 (Thorndike and Colony, 1982; Kreyscher et al., 2000;

315 Leppäranta, 2011; Shu et al., 2012), Re ranges from $8.7 \times 10^{4}$ to $1.1 \times 10^{8}$ in the Arctic

316 Ocean. Field experiments have been performed to study the turbulent boundary-layer

317 under sea ice (McPhee, 2002 and 2008).
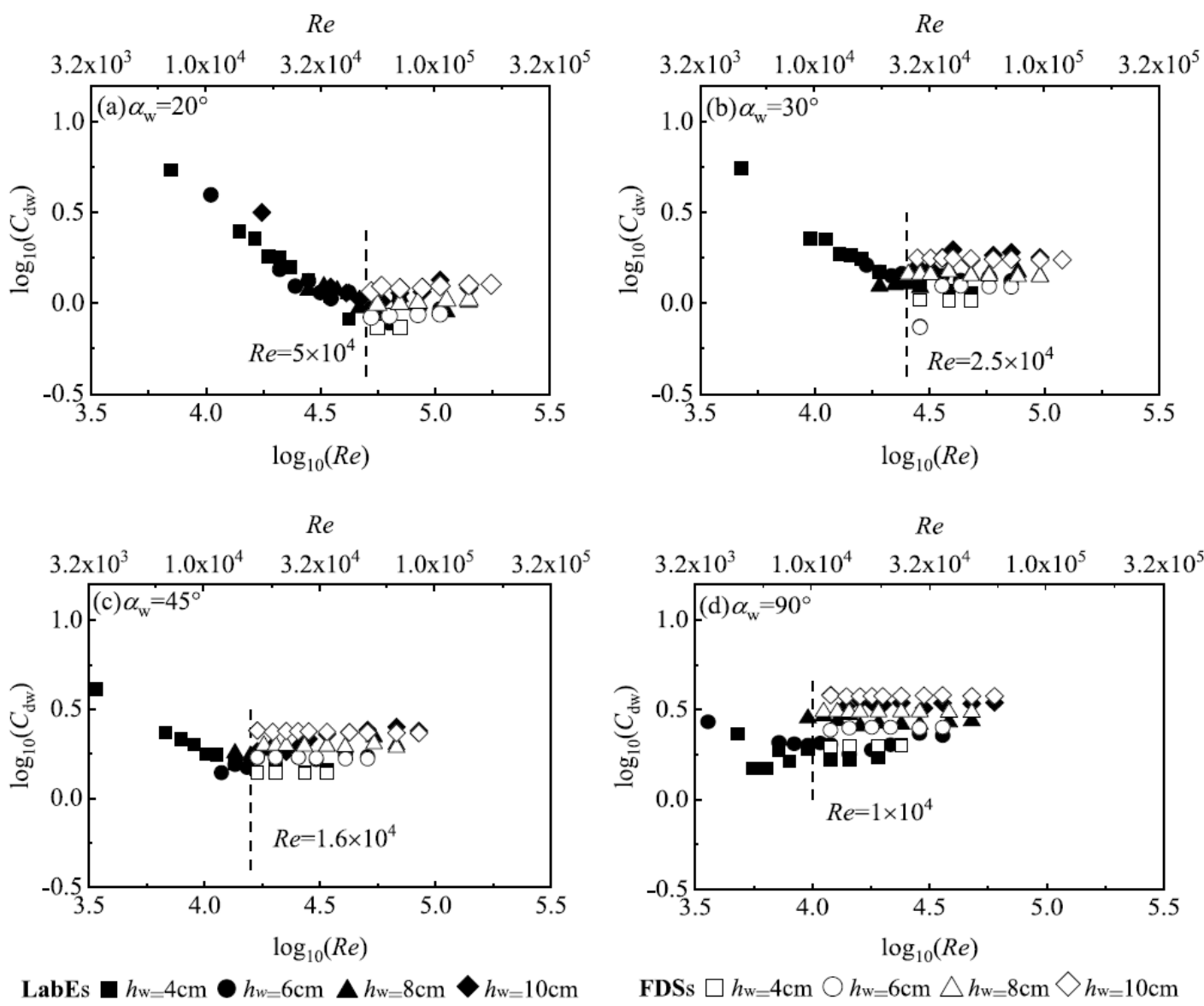

Figure 3. Plots of $\log _{10}\left(C_{\mathrm{dw}}\right)$ with $\log _{10}(R e)$ at keel depths $h=4 \mathrm{~cm}, 6 \mathrm{~cm}, 8 \mathrm{~cm}$, and

$10 \mathrm{~cm}$. Open circles represent FDSs (see details in Section 4.2), and solid circles

represent LabEs. The keel slope angle $\alpha_{\mathrm{w}}$ is (a) $20^{\circ}$, (b) $30^{\circ}$, (c) $45^{\circ}$, and (d) $90^{\circ}$. The 
323

328 linear least-squares regression. The result was $C_{\mathrm{dw}}(R e)=4100 \cdot R e^{-0.5}$, with the 329 coefficient of determination $R^{2}=0.79$ passing the significance test $(F$-test, $p<0.001)$.

330 Fig. 4 shows that $C_{\mathrm{dw}}$ depended only on $R e$, which was similar to previous studies, i.e., 331 Hoerner (1965) and Pite (1995) found that the friction coefficient of a flat plate obeyed 332 a $R e^{-0.5}$ power-law in the laminar region where the viscous shear stress dominated the 333 drag force.

334

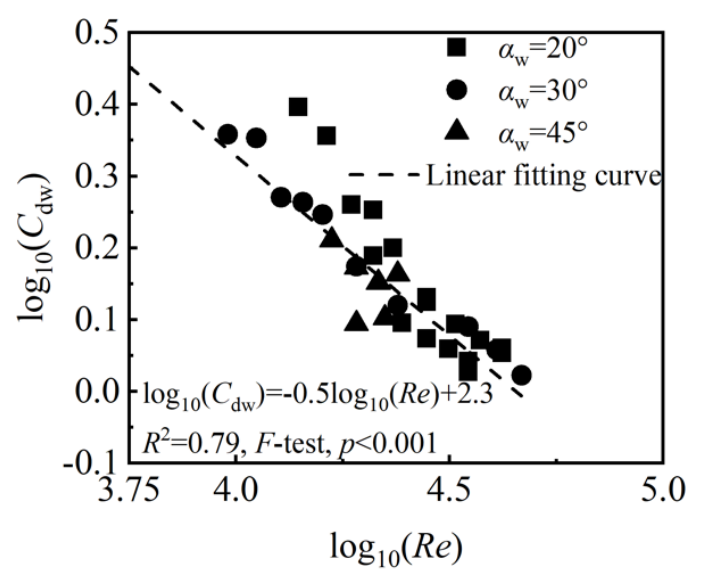

336 Figure 4. The laminar flow results for all keel shapes and linear least-squares regression fit. 
FDSs consider the turbulent regime. The relative velocity $u / U$ induced by a

341 triangular geometry is presented in Fig. 5a. The streamlines around the keel were no

342 longer smooth, and a vortex wake formed at the lee side (Fig. 5a). Behind the keel, a

343 sheltered area formed (Garbrecht et al., 1999), where the pressure was lower than the

344 pressure at the same level at the front of the keel, and the form drag force created by

345 the pressure difference was much greater than the skin friction drag force.

347 geometry gradually weakened. Figs. 5b-f show a series of velocity profiles along the 348 horizontal direction. $D / h_{\mathrm{w}}=3.5$ had a uniform upstream velocity profile with a very 349 thin bottom boundary layer (when $u / U=0.99, z / h_{\mathrm{w}} \approx 0.2$ ). Directly below the keel, the 350 flow accelerated because the keel narrowed the flume. At the same time, the velocity 351 near the keel corner rapidly increased from 0 to the mean streamwise velocity of about $3521.7 U$. When $x / h_{\mathrm{w}}=5$, a wake area formed behind the keel with negative $x$-velocity on 353 top. Due to the disturbance by the keel, a turbulent boundary-layer existed in the upper 354 water of the flume. With increasing $x / h_{\mathrm{w}}$, the thickness of the boundary-layer gradually 355 developed downward. 
(a)
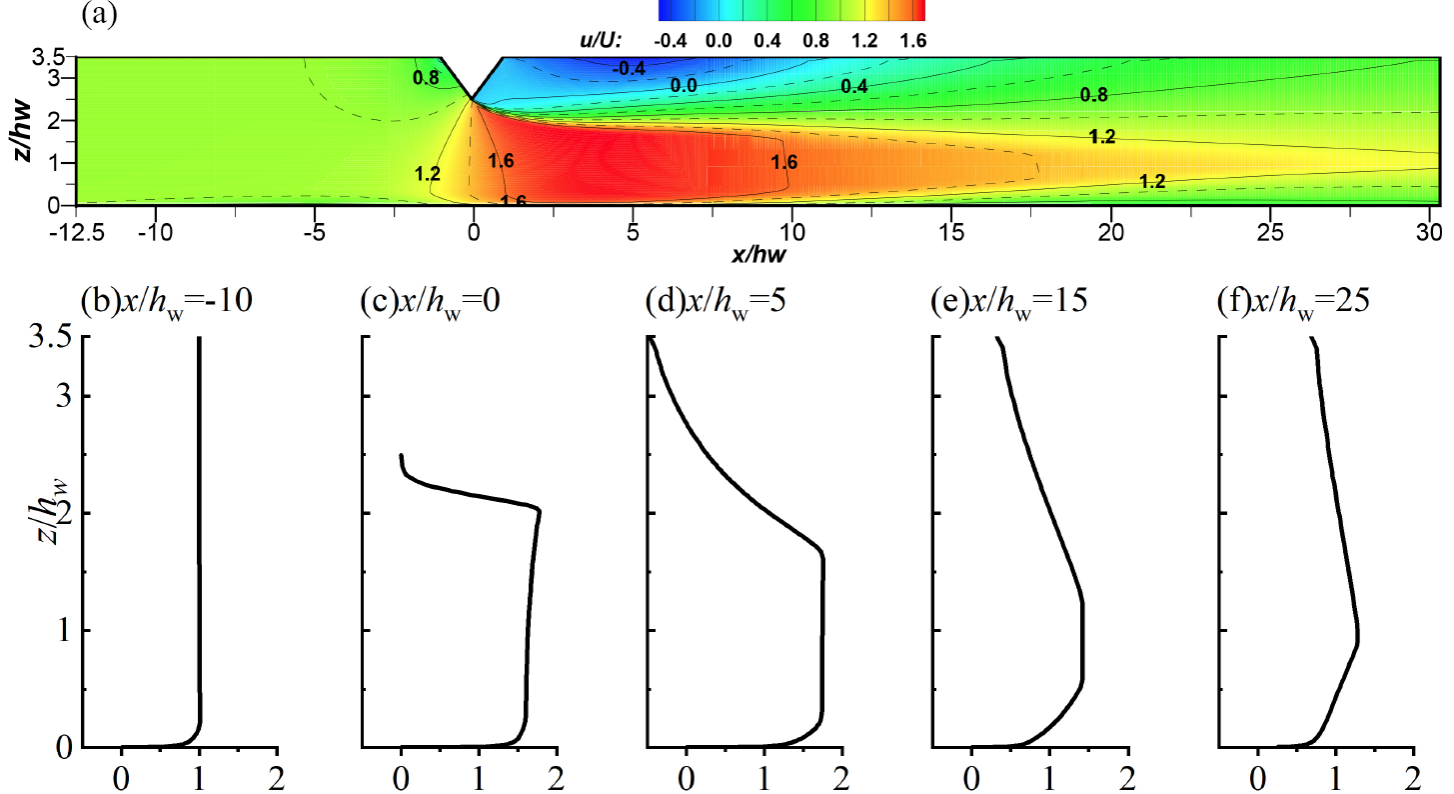

(c) $x / h_{\mathrm{w}}=0$

(d) $x / h_{\mathrm{w}}=5$

(e) $x / h_{\mathrm{w}}=15$

(f) $x / h_{\mathrm{w}}=25$
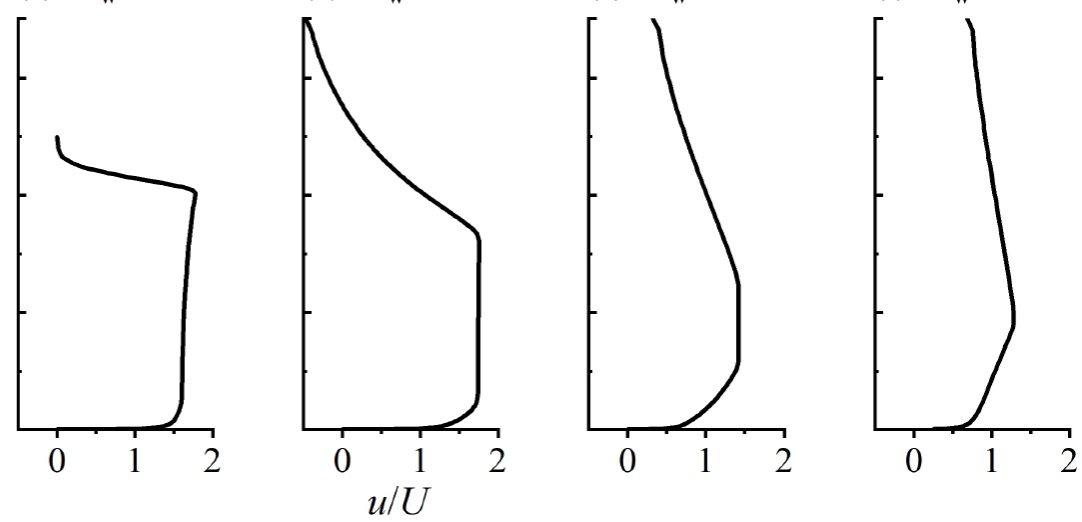

Figure 5. (a) Example of velocity field with $\alpha_{\mathrm{w}}=45^{\circ}, D / h_{\mathrm{w}}=3.5$, and $U=0.3 \mathrm{~m} / \mathrm{s}$ and a

series of $x$-velocity $u$ profiles along the horizontal direction: (b) $x / h_{\mathrm{w}}=-10$, (c) $x / h_{\mathrm{w}}=0$,

(d) $x / h_{\mathrm{w}}=5$, (e) $x / h_{\mathrm{w}}=15$, and (f) $x / h_{\mathrm{w}}=25$. FDSs varied within $0.17-3.78$ with $\alpha_{\mathrm{w}}$ and $h_{\mathrm{w}}$, which were two factors affecting $C_{\mathrm{dw}}$. 
370 presents the comparison between FDS results and LabE measurements, which are also

371 consistent with a logarithmic variation.

373 value of the ratio of water depth $D$ to keel depth $h_{\mathrm{w}}$ was 8.75 . The keel depth affected

374 the mean streamwise velocity and the pressure distribution around the keel. The 375 variations in $C_{\mathrm{dw}}\left(D / h_{\mathrm{w}}\right)$ when $U=0.15 \mathrm{~m} / \mathrm{s}$ and $\alpha_{\mathrm{w}}=45^{\circ}$ are shown in Fig. $6 \mathrm{~b}$ as an example. As shown in Fig. $6 \mathrm{~b}, C_{\mathrm{dw}}$ decreases with $D / h_{\mathrm{w}}$, being sensitive at small $D / h_{\mathrm{w}}$. The increase in the keel depth obviously leads to an increase in the mean streamwise velocity at the keel. According to the Bernoulli equation, the sum of static and dynamic pressure, $p+\frac{1}{2} \rho U^{2}$, is a constant along streamlines. Thus, the drag force (also referred 380 as the pressure difference $\triangle p$ ) is proportional to $\frac{1}{2} \rho \Delta U^{2}$. When the keel depth $h_{\mathrm{w}}$ 381 increases, the channel section becomes narrower, and according to the law of mass 382 conservation, $\frac{1}{2} \triangle U^{2}=\frac{1}{2}\left(h_{\mathrm{w}} /\left(D-h_{\mathrm{w}}\right)\right)^{2} U^{2}$. Consequently, $C_{\mathrm{dw}} \sim \triangle p / \rho U^{2}=1 /\left(2\left(D / h_{\mathrm{w}^{-}}\right.\right.$ $3831)^{2}$ ). Based on this proportionality, we obtained the formula by the best linear fit to 384 laboratory data between $C_{\mathrm{dw}}$ and $1 /\left(D / h_{\mathrm{w}}-1\right)^{2}$, as shown in Fig. $6 \mathrm{~b}$. The coefficient of 385 determination was $R^{2}=0.97$, and the significance level was less than 0.05 . As $D$ 386 increased, the influence of $h_{\mathrm{w}}$ on $C_{\mathrm{dw}}$ weakened with $C_{\mathrm{dw}} \rightarrow 1.37$ for $D \gg h_{\mathrm{w}}$. The 387 variation of $C_{\mathrm{dw}}$ with $D / h_{\mathrm{w}}$ in FDS was also validated by the $\mathbf{L a b E}$ measurements in 388 Fig. 6b. Thus, the FDS is feasible to examine the form drag coefficient $C_{\mathrm{dw}}$. 

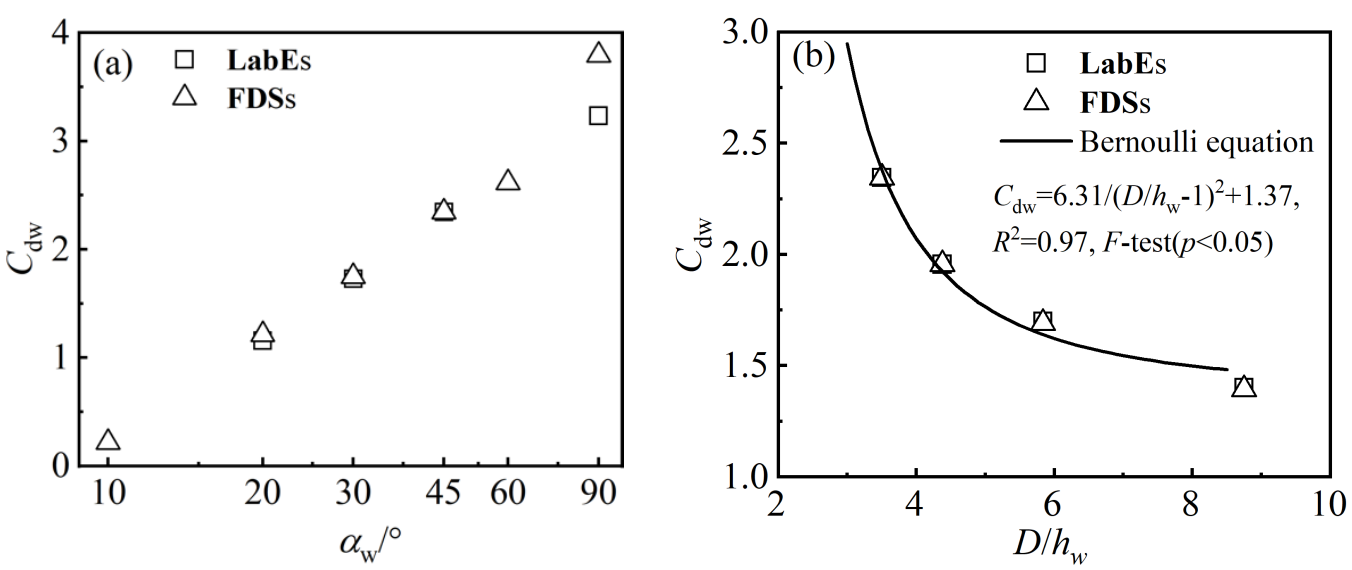

390

Figure 6. Variation of $C_{\mathrm{dw}}$ with (a) $\alpha_{\mathrm{w}}\left(10^{\circ} \leq \alpha \leq 90^{\circ}\right)$ when $U=0.15 \mathrm{~m} / \mathrm{s}$ and $h_{\mathrm{w}}=10 \mathrm{~cm}$ in LabEs and FDSs (note: logarithmic scale for $\alpha_{\mathrm{w}}$ ) for the turbulent regime, and (b) $D / h_{\mathrm{w}}\left(h_{\mathrm{w}}=4 \mathrm{~cm}, 6 \mathrm{~cm}, 8 \mathrm{~cm}\right.$, and $\left.10 \mathrm{~cm}, D=35 \mathrm{~cm}\right)$ when $U=0.15 \mathrm{~m} / \mathrm{s}$ and $\alpha=45^{\circ}$.

\subsection{Deep Water Consideration for FDS}

In the real ocean, the mixed layer formation has seasonal characterisics. In summer, the mixed-layer depth tends to be small, since meltwater creates a stable stratification. Then we have $D / h_{\mathrm{w}} \sim 1$, and it is not appropriate to compare the tank water depth and the mixed layer depth in real ocean. In other seasons, $D / h_{\mathrm{w}}>>1$ is mostly acceptable (e.g. McPhee, 2002; Strub-Klein and Sudom, 2012; Peralta-Ferriz and Woodgate, 2015). When the mixed layer depth is of the same magnitude as the keel depth, the mixed layer would be deepening along with the keel movement, which is beyond the scope of this study.

Additional FDS simulations for such condtions were therefore carried out. Assuming asymptotic conditions, we have turbulent flows where $R e$ and $D / h_{\mathrm{w}}$ tend to 
406 infinity. Then, the parametrization of $C_{\mathrm{dw}}=f\left(R e, D / h_{\mathrm{w}}, \alpha_{\mathrm{w}}\right)$ would be independent of $R e$ 407 and $D / h_{\mathrm{w}}$ and has a simple functional form of $C_{\mathrm{dw}}\left(\alpha_{\mathrm{w}}\right)$. We configured a variable water depth, $D=35-140 \mathrm{~cm}$, in the FDS simulations.

409 Fig. 7a shows that $C_{\mathrm{dw}}$ was more sensitive to $h_{\mathrm{w}}$ in shallow water than in deep water. In 410 the shallow water conditions, the keel may induce disturbances around the halocline, 411 and internal waves can also be generated in the pycnocline in the real ice-covered ocean 412 (Fer et al., 2014; McPhee, 2002; Pite et al., 1995), which will be considered in further 413 studies. With the increase of $D / h_{\mathrm{w}}$, the influence of $h_{\mathrm{w}}$ on the drag force becomes small 414 compared to variations arising from $\alpha_{\mathrm{w}}$, as shown in Figs. $7 \mathrm{~b}$ and 9 . When $D / h_{\mathrm{w}} \geq 14$ $415(D=140 \mathrm{~cm}), C_{\mathrm{dw}}$ tends to be independent of the water depth at a fixed slope angle.
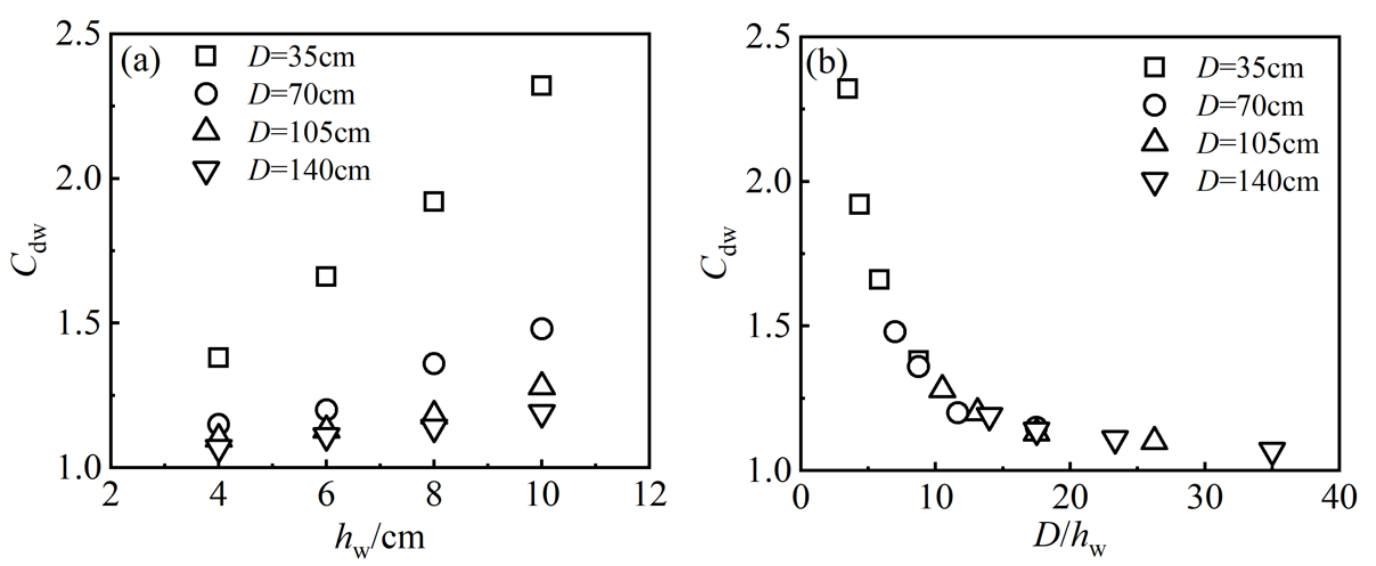

418 Figure 7. (a) Variations of $C_{\mathrm{dw}}$ with $h_{\mathrm{w}}$ and $D$ for $U=0.3 \mathrm{~m} / \mathrm{s}$ (turbulent regime) and $\alpha=45^{\circ}$, and (b) the dimensionless relationship between $C_{\mathrm{dw}}$ and $D / h_{\mathrm{w}}$. 
423 in Fig. 8, where the bottom boundary had only a minor effect on flow past the keel. The 424 velocity profiles are shown in the Supporting information as Figure $\mathrm{S} 1 . C_{\mathrm{dw}}$ tended to 425 a stable limit with $R e$ at a constant keel angle in the turbulent regime. However, the 426 variation of $C_{\mathrm{dw}}$ with $h_{\mathrm{w}}$ was much less than in the shallow depth case (Fig. 6b) with $427 C_{\mathrm{dw}} \sim 0.5 /\left(D / h_{\mathrm{w}}-1\right)^{2}$. When $D=140 \mathrm{~cm}$ and $D / h_{\mathrm{w}} \geq 14$, the variation of $h_{\mathrm{w}}$ had only a 428 minor effect on $C_{\mathrm{dw}}$. For example, $C_{\mathrm{dw}}$ increased by less than $1 \%$ from $h_{\mathrm{w}}=4 \mathrm{~cm}$ to $h_{\mathrm{w}}$ $429=10 \mathrm{~cm}$ with $\alpha_{\mathrm{w}}=20^{\circ}$. For larger $\alpha_{\mathrm{w}}, h_{\mathrm{w}}$ still had some influence on $C_{\mathrm{dw}}$ (Figs. 8e-f), 430 because the sheltered area behind a sharp keel increased more with $h_{\mathrm{w}}$ compared with 431 a gently sloping keel. At $\alpha_{\mathrm{w}}=45^{\circ}, C_{\mathrm{dw}}$ decreased from 1.25 to 1.1 for $D / h_{\mathrm{w}}$ increasing 432 from 14 to 35 . But the keel angle $\alpha_{\mathrm{w}}$ still had a significant influence on $C_{\mathrm{dw}}$, in a way 433 that resembles the variation law shown in Fig. 6a.

434
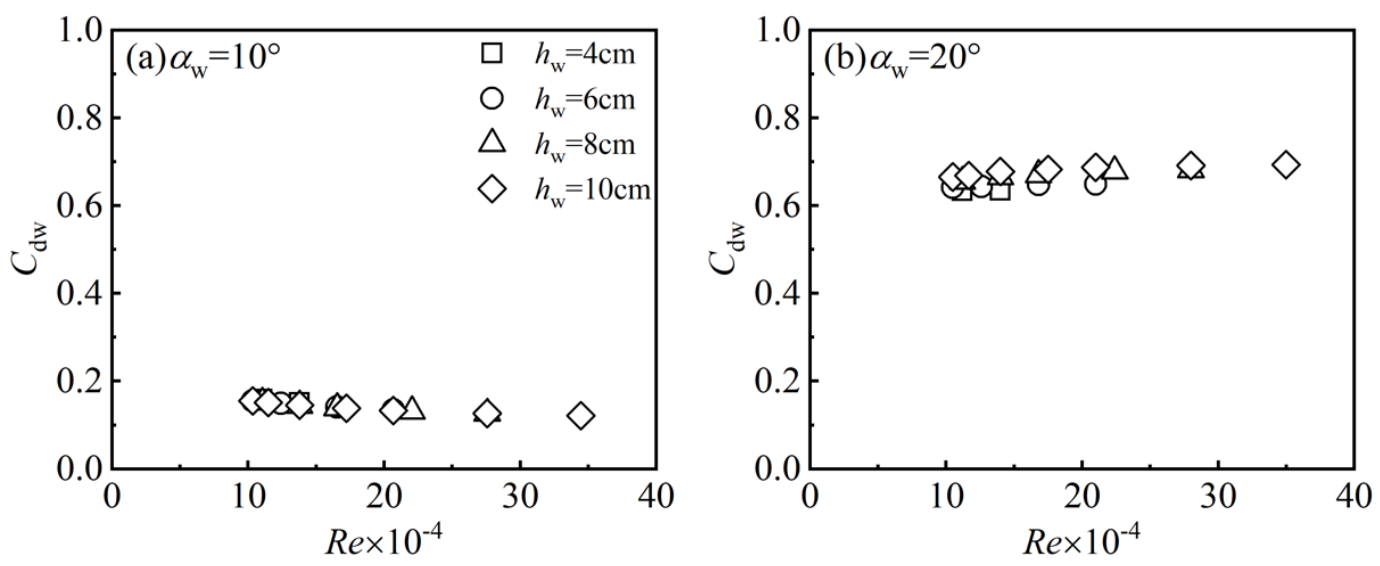

435 

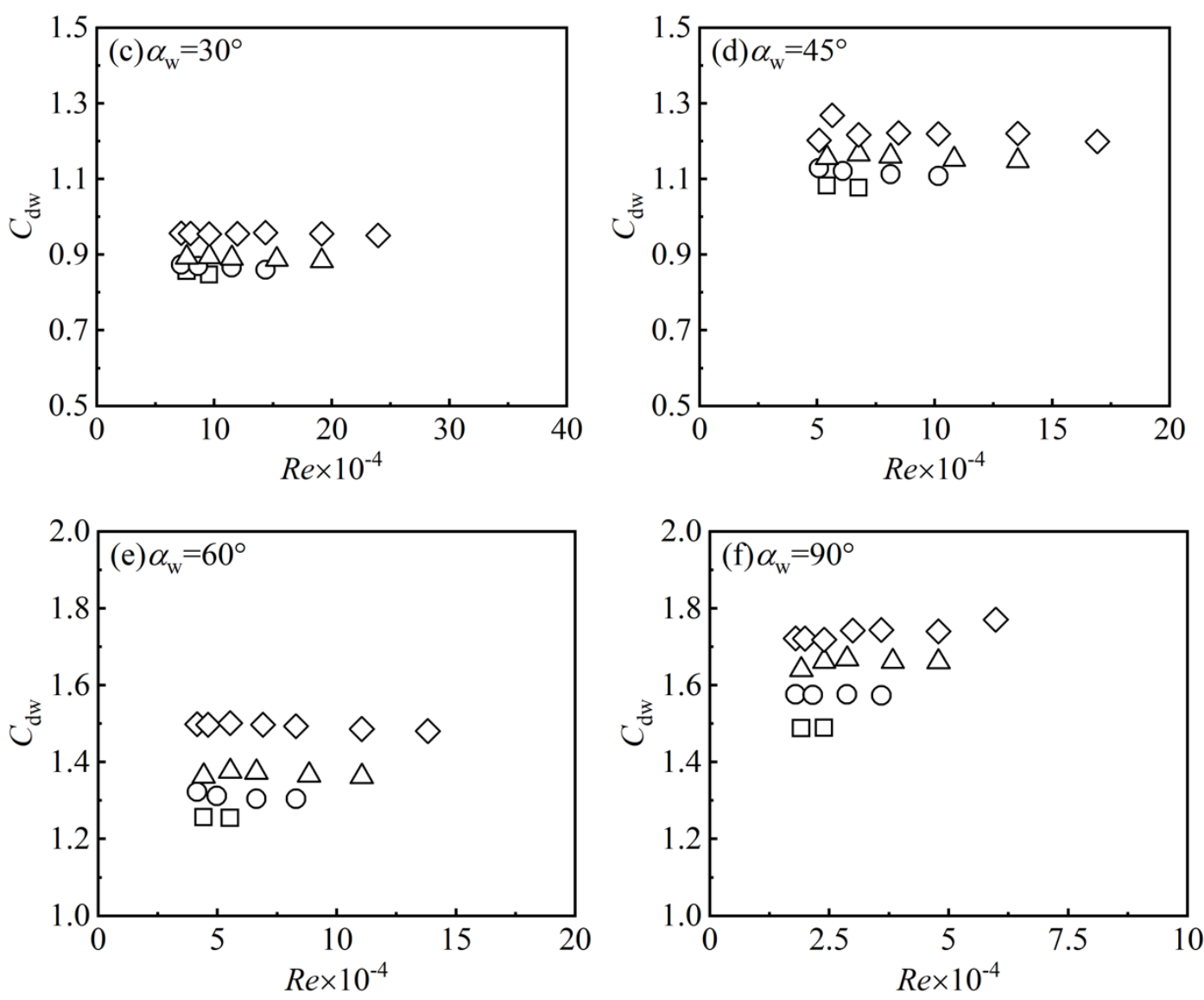

437 $\alpha_{\mathrm{w}}<90^{\circ}$. The results in Fig. 9 include all extended FDS cases, each point calculated as the mean value over all cases with a constant slope. A logarithmic fit was determined as:

Figure 8. $C_{\mathrm{dw}}$ results for deep water $\left(D / h_{\mathrm{w}} \geqslant 14\right)$ obtained from extended FDSs when

$$
h_{\mathrm{w}}=4 \mathrm{~cm}, 6 \mathrm{~cm}, 8 \mathrm{~cm} \text {, and } 10 \mathrm{~cm}(D=140 \mathrm{~cm}):\left(\text { a) } \alpha_{\mathrm{w}}=10^{\circ},(\mathbf{b}) \alpha_{\mathrm{w}}=20^{\circ},(\mathbf{c}) \alpha_{\mathrm{w}}=\right.
$$$$
30^{\circ}, \text { (d) } \alpha_{\mathrm{w}}=45^{\circ}, \text { (e) } \alpha_{\mathrm{w}}=60^{\circ} \text {, and (f) } \alpha_{\mathrm{w}}=90^{\circ} \text {. }
$$

According to the above analysis, the influence of the $R e$ and $h_{\mathrm{w}}$ on $C_{\mathrm{dw}}$ in deep water is weak in turbulent flow. Next, we pay attention to the relationship between $C_{\mathrm{dw}}$ and the keel angle $\alpha_{\mathrm{w}}$. Fig. 9 illustrates that $C_{\mathrm{dw}}$ increased from 0.17 to 1.66 for $10^{\circ}<$

$$
C_{\mathrm{dw}}=0.68 \cdot \ln \left(\alpha_{\mathrm{w}} / 7.8^{\circ}\right), 7.8^{\circ}<\alpha_{\mathrm{w}}<90^{\circ} .
$$


449 The coefficient of determination was $R^{2}=0.998$, which was above the significance level 450 ( $F$-test, $p<0.001)$. Note that Eq. (15) is only valid for angles greater than $7.8^{\circ}$, 451 suggesting that for samaller angles $C_{\mathrm{dw}} \approx 0$.

453

460 between $C_{\mathrm{da}}$ and $\alpha_{\mathrm{a}}: C_{\mathrm{da}}=0.012+0.012 \alpha_{\mathrm{a}}$. The different forms between air-ice and ice-

Figure 9. Relationship between $C_{\mathrm{dw}}$ and $\alpha_{\mathrm{w}}$ in deep water conditions.

Field observations and underwater sonar data have shown that keel slope angle has a log-normal distribution and more than $90 \%$ of the measured angles were greater than $8^{\circ}$, with the mean value of $23.2^{\circ}$ (Davis and Wadhams, 1995) and $26.6^{\circ}$ (FY ice, Timco and Burden, 1997). With the $\alpha_{\mathrm{w}}$ of $23.2^{\circ}-26.6^{\circ}$, the coefficient $C_{\mathrm{dw}}$ is $0.74-0.83$ according to Eq. (15). This range is close to the upper limit of the form drag coefficient of ridge sails, $C_{\mathrm{da}}$, summarized as $0.2-0.8$ (Garbrecht et al., 1999). Banke et al. (1976) made field observations over the air-ice interface and obtained a linear relationship

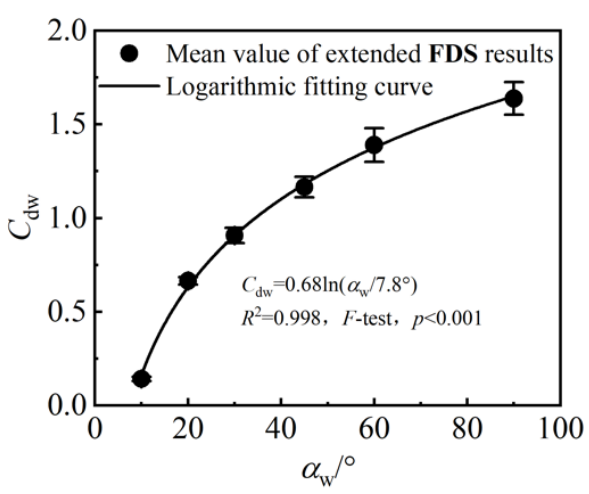


465 466 467

number of sample points and the way of approach in the fitting. Anyway, the results obtained here show that $C_{\mathrm{dw}}$ is larger than $C_{\mathrm{da}}$.

\section{Discussions}

Dimensional analysis for LabE and FDS ensured a straightforward derivation of the impact of the keel geometry on the local drag coefficient, $C_{\mathrm{dw}}=f\left(R e, D / h_{\mathrm{w}}, \alpha_{\mathrm{w}}\right)$. In the asymptotic conditions with $R e$ and $D / h_{\mathrm{w}}$ assumed to be very large, $C_{\mathrm{dw}}$ depends only on $\alpha_{\mathrm{w}}$ as shown in Eq. (15). It is interesting to understand this new effect of keel geometry on the parameterization formulae of the total ice-ocean drag coefficient as Eqs. (2-5), and its application in sea-ice dynamic models.

\subsection{Sea Ice Topography and Keel Drag Coefficient}

Except for $\alpha_{\mathrm{w}}$, three ice geometry parameters are also included in the $C_{\mathrm{w}}$ and $C_{\mathrm{Rw}}$ formulae (Eqs. 2-5): the ice concentration $A(0 \leq A \leq 1)$, the floe aspect ratio of draft to length $d_{\mathrm{w}} / L_{f}$, and the ridging intensity $h_{\mathrm{w}} / L_{\mathrm{r}}$. Due to the form drag, the total drag force depends on ice concentration (Andreas et al., 2010) in a nonlinear manner for both air-ice and ice-ocean interface (Lu et al., 2011; Lüpkes et al., 2012). A previous sensitivity study (Lu et al., 2011) has shown that when $A=0.8$, the ice-ocean drag coefficient $C_{\mathrm{w}}$ reached the maximum. Therefore, we selected $A=0.8$ as the focus of interest.

The floe size parameters covary with thickness and may be occasionally related to ice concentration (Zhang et al., 2015; Roach et al., 2017). A rough approximation based on Mai (1996) was used by Lüpkes and Birnbaum (2005): 


$$
L_{f}=d_{a} \frac{31}{1-A}
$$

487 where $d_{\mathrm{a}}$ is the floe freeboard. Eq. (17) resembles the parametrization of floe length and 488 freeboard in the marginal ice zone by Lüpkes et al. (2012). For an ice density of 918 $489 \mathrm{~kg} / \mathrm{m}^{3}$ (Doble et al., 2011), the ratio of floe draft to freeboard is $d_{\mathrm{w}} / d_{\mathrm{a}} \approx 8.9$, and thus $490 d_{\mathrm{w}} / L_{\mathrm{f}} \approx 0.29(1-A)$. Using this relation, we chose a typical ice concentration $A$ to 491 determine $d_{\mathrm{w}} / L_{\mathrm{f}}$ in the sensitivity analysis. Ice floe size affects the sea-ice thickness 492 distribution via mechanical deformation processes (Mårtensson et al., 2012; Roach et al., 2017), including the ridged or deformed ice thickness distribution.

To investigate the effect of the keel geometry on the form drag, the ice 495 concentration and floe aspect ratio were set as constants, $A=0.8$ and $d_{\mathrm{w}} / L_{\mathrm{f}}=0.06$ (from 496 Eq. 17), and the keel geometry parameters $h_{\mathrm{w}} / L_{\mathrm{r}}$ and $\alpha_{\mathrm{w}}$ are the variables in the sensivity 497 studies. The magnitude of $h_{\mathrm{w}} / L_{\mathrm{r}}$ varied from 0.001 to 0.1 and $\alpha_{\mathrm{w}}$ varied from $10^{\circ}-90^{\circ}$ 498 according to field observations (Davis and Wadhams, 1995; Brenner et al., 2020). The 499 relevant ice geometry parameters are listed in Table 5. The sensitivity of the total ice500 ocean drag coefficient $C_{\mathrm{Rw}}$ and the keel drag coefficient $C_{\mathrm{w}}$ was investigated by 501 covarying the ice geometry parameters and the function $C_{\mathrm{dw}}\left(\alpha_{\mathrm{w}}\right)$.

Table 5. Geometry parameters of sea-ice bottom.

\begin{tabular}{cc}
\hline Ice parameters & Bottom value \\
\hline Keel slope angle & $\alpha_{\mathrm{w}}=10^{\circ}-90^{\circ}$ \\
Ratio of keel depth to spacing & $h_{\mathrm{w}} / L_{\mathrm{r}}=0.001-0.1$ \\
Ratio of ice draft to floe length & $d_{\mathrm{w}} / L_{\mathrm{f}}=0.06$
\end{tabular}


Ice concentration

Local ice lateral coefficient

Local form coefficient of a keel

Local ice frictional coefficient

$$
\begin{gathered}
A=0.8 \\
C_{\mathrm{e}}=1 \\
C_{\mathrm{dw}}=0.68 \ln \left(\alpha / 7.8^{\circ}\right) \\
C_{\mathrm{s}}=0.002
\end{gathered}
$$

504

506 the influence of $\alpha_{\mathrm{w}}$ on $C_{\mathrm{dw}}, C_{\mathrm{Rw}}$ varied greatly, increasing quickly with increasing $\alpha_{\mathrm{w}}$

507 for $10^{\circ} \leq \alpha_{\mathrm{w}} \leq 50^{\circ}$ and $h_{\mathrm{w}} / L_{\mathrm{r}} \geq 0.01$, from $0.4 \times 10^{-3}$ to $15 \times 10^{-3}$. A similar trend of

$508 C_{\mathrm{Rw}} / C_{\mathrm{w}}$ with $\alpha_{\mathrm{w}}$ and $h_{\mathrm{w}} / L_{\mathrm{r}}$ is shown in Fig. $10 \mathrm{~b}$. With the increase of $h_{\mathrm{w}} / L_{\mathrm{r}}, C_{\mathrm{Rw}}$

509 gradually becomes the main part in $C_{\mathrm{w}}$. When $h_{\mathrm{w}} / L_{\mathrm{r}} \geq 0.01$ and $\alpha_{\mathrm{w}} \leq 50^{\circ}$, the variation

510 of $C_{\mathrm{Rw}} / C_{\mathrm{w}}$ was highly dramatic because $C_{\mathrm{Rw}}$ is proportional the geometry-based

$511 C_{\mathrm{dw}}\left(\alpha_{\mathrm{w}}\right)$.
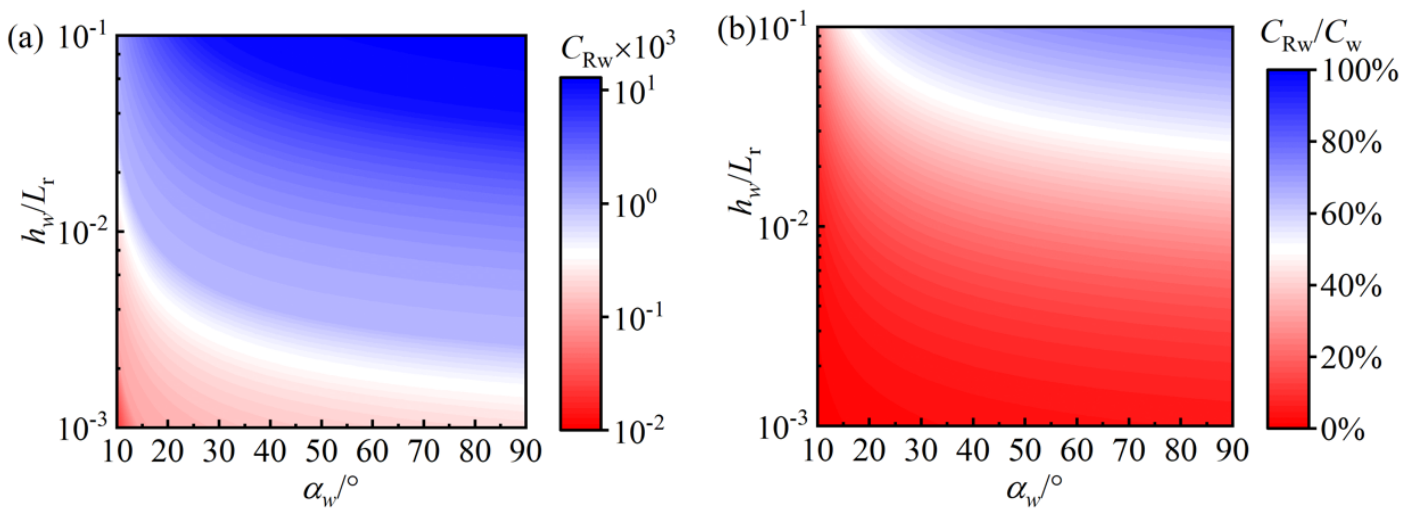

514 Figure 10. (a) Variations of $C_{\mathrm{Rw}}$ with $\alpha_{\mathrm{w}}$ and $h_{\mathrm{w}} / L_{\mathrm{r}}$ when $A=0.8$; (b) Variations of 
519 intensity, how to select a representative $\alpha_{\mathrm{w}}$ to calculate $C_{\mathrm{dw}}$ is important. In the Arctic

520 Ocean, the keel slope angle has been shown to follow the log-normal distribution (Davis

521 and Wadhams, 1995; Timco and Burden, 1997). Based on this distribution, the averaged

522 value of the local drag coefficient can be calculated as

$$
\begin{gathered}
\overline{C_{\mathrm{dw}}}=\int_{8}^{90} C_{d w}\left(\alpha_{w}\right) p\left(\alpha_{w}\right) d \alpha_{w} \\
=\int_{0.03}^{2.45} 0.68 * \ln \left(\frac{\alpha_{w}}{7.8^{\circ}}\right) \frac{1}{\sigma \sqrt{2 \pi}} \exp \left[-\frac{1}{2 \sigma^{2}}\left(\ln \left(\frac{\alpha_{w}}{7.8^{\circ}}\right)-(\mu-\ln 7.8)\right)^{2}\right] d \ln \left(\frac{\alpha_{w}}{7.8^{\circ}}\right) \\
=0.75
\end{gathered}
$$

526 where $\ln \left(\alpha_{\mathrm{w}}\right) \sim N(3.17,0.0028), \mu=3.17$ and $\sigma=0.0531$. The integration in the second

527 line of Eq. (16) is simplified by the normality of $\ln \left(\alpha_{\mathrm{w}} / 7.8^{\circ}\right)$ and considered as the 528 product of the factor of 0.68 and the rest of the integral equal to 1.11 . Note that the 529 integration limits of $\ln \left(\alpha_{\mathrm{w}} / 7.8^{\circ}\right)$ should be $(-\infty,+\infty)$ in the normal distribution. However, 530 we found that the interval $(0.03,2.45)$ covered the main part of the integral and only

531 very little was left for the rest beyond. The averaged value $\overline{C_{\mathrm{dw}}}$ is 0.75 , corresponding 532 to a mean keel slope angle of $23.5^{\circ}$ (Fig. 9). This value was larger than $\overline{C_{\mathrm{dw}}}=0.5$ in 533 LU2011 and $0.13-0.39$ in TS2014 (the coefficient in TS2014 can be converted by a 534 factor of $2 C_{\mathrm{h}} / \pi \approx 0.76$ compared to this study, for details see Supporting information 535 Text S1). 
554 sensitivity study of the keel drag coefficient $C_{\mathrm{Rw}}$ and the total ice-ocean drag coefficient

$555 C_{\mathrm{w}}$. When the ridging intensity was $h_{\mathrm{w}} / L_{\mathrm{r}} \geq 0.01, C_{\mathrm{Rw}}$ increased monotonously and 556 quickly for $\alpha_{\mathrm{w}}$ within $10^{\circ}-50^{\circ}$. Pressure ridges in Arctic seas show large variability in 557 morphology, and the keel slope angles are mainly within $10^{\circ}-90^{\circ}$ (Davis and Wadhams, 
558

560

561

562 coefficient averaged over $\alpha_{\mathrm{w}}, \overline{C_{\mathrm{dw}}}$, as an approximation. Assuming the log-normal

563 distribution of the keel angle, the average is $\overline{C_{\mathrm{dw}}}=0.75$, which is larger than the

564 empirical constant of 0.5 used earlier in LU2011 or the range of $0.13-0.39$ used in

565 TS2014. Thus, we may further question the effect of the keel geometry distributions on

$566 C_{\mathrm{dw}}$. Multiyear ridges tend to have different shapes than first-year ridges, and there may

567 be seasonal variations in that summertime ridges are smoother than wintertime ridges,

568 as well as variations between different seas.

570 sea ice have also been changing. In sea-ice dynamic models, the ice thickness

571 distribution is adjusted by dynamic and thermodynamic processes. Thinner sea ice is

572 more easily subject to deformation, resulting in sea-ice ridging or hummocking

573 (Leppäranta, 2011). The redistribution of deformed and undeformed ice has an

574 influence on ice morphology including the keel slope angle, and also the amount of

575 ridging further affects the drift of sea ice. Therefore, the effect of the keel shape on the

576 form drag coefficient is crucial in short-term sea-ice forecasting, as well as in

577 climatological sea-ice models. Further work is needed to model the keel drag coefficient 
578 for more general conditions including shallow mixed-layers due to salinity stratification

579 in summer.

\section{Acknowledgements}

582 We thank two anonymous reviewers for constructive comments to significantly

583 improve the text. This research was supported by the National Key R\&D Program of 584 China No 2019YFE0197600, the National Natural Science Foundation of China (Grant 585 No. 41922045, 41876213 and 41876219), the Academy of Finland (Grant No. 333889 586 and 317999), and the Fundamental Research Funds for the Central Universities 587 (DUT20GJ206).

\section{Data Availability Statement}

589 The LabE measurements and FDS dataset in this research can be accessed via the 590 website (https://doi.org/10.5281/zenodo.4592938).

\section{$591 \quad$ References}

592 Arya, S. P. S. (1973). Contribution of form drag on pressure ridges to the air stress on 593 arctic ice. Journal of Geophysical Research, 78(30), 7092-7099. 594 https://doi.org/10.1029/JC078i030p07092

595 Arya, S. P. S. (1975). A drag partition theory for determining the large-scale roughness 596 parameter and wind stress on the Arctic pack ice. Journal of Geophysical Research, 597 80(24), 3447-3454. https://doi.org/10.1029/JC080i024p03447 
598 Banke, E. G., \& Smith S. D. (1975). Measurement of form drag on ice ridges. AIDJEX 599 Bull., 28, 21-27.

600 Banke, E. G., Smith, S. D., \& Anderson, R. J. (1976). Recent measurements of wind 601 stress on Arctic sea ice. Journal of the Fisheries Research Board of Canada, 33(10), 602 2307-2317. https://doi.org/10.1139/f76-277

603 Banke, E. G., Smith, S. D., \& Anderson, R. J. (1980). Drag coefficients at AIDJEX from 604 sonic anemometer measurements. Sea Ice Processes and Models, 430-442.

605 Bi, H., Liang, Y., Wang, Y., Liang, X., Zhang, Z., Du, T., Yu, Q., Huang, J., Kong, M., 606 \& Huang, H. (2020). Arctic multiyear sea ice variability observed from satellites: a 607 review. Journal of Oceanology and Limnology, 38(4), 962-984. 608 https://doi.org/10.1007/s00343-020-0093-7

609 Bitz, C. M., Holland, M. M., Weaver, A. J., \& Eby, M. (2001). Simulating the ice610 thickness distribution in a coupled climate model. Journal of Geophysical Research:

611 Oceans, 106(C2), 2441-2463. https://doi.org/10.1029/1999JC000113

612 Blackadar, A. K., \& Tennekes, H. (1968) Asymptotic similarity in neutral barotropic 613 planetary boundary layers. Journal of the Atmospheric Sciences, 25(6), 1015-1020. 614 https://doi.org/10.1175/1520-0469(1968)025<1015:ASINBP>2.0.CO;2

615 Bonath, V., Petrich, C., Sand, B., Fransson, L., \& Cwirzen, A. (2018). Morphology, 616 internal structure and formation of ice ridges in the sea around Svalbard. Cold Regions 617 Science $\quad$ and $\quad$ Technology, 263-279. 
618 https://doi.org/10.1016/j.coldregions.2018.08.011

619 Brenner, S., Rainville, L., Thomson, J., Cole, S., \& Lee, C. (2020). Comparing 620 observations and parameterizations of ice-ocean drag through an annual cycle across 621 the Beaufort Sea. Journal of Geophysical Research: Oceans, First posted online. 622 https://doi.org/10.1029/2020JC016977

623 Castellani, G., Lüpkes, C., Hendricks, S., \& Gerdes, R. (2014). Variability of Arctic 624 sea-ice topography and its impact on the atmospheric surface drag. Journal of 625 Geophysical Research: $\quad$ Oceans, 6743-6762. 626 https://doi.org/10.1002/2013JC009712

627 Chanona, M., Waterman, S., \& Gratton, Y. (2018). Variability of Internal Wave-Driven 628 Mixing and Stratification in Canadian Arctic Shelf and Shelf-Slope Waters. Journal of 629 Geophysical Research: Oceans, 123(12), 9178-9195. 630 https://doi.org/10.1029/2018JC014342

631 Comiso, J. C. (2012). Large decadal decline of the Arctic multiyear ice cover. Journal 632 of Climate, 25(4), 1176-1193. https://doi.org/10.1175/JCLI-D-11-00113.1

633 Davis, N. R., \& Wadhams, P. (1995). A statistical analysis of Arctic pressure ridge 634 morphology. Journal of Geophysical Research, 100(C6), 10915-10925. 635 https://doi.org/10.1029/95JC00007

636 Doble, M. J., Skourup, H., Wadhams, P. \& Geiger, C. A. (2011). The relation between 637 arctic sea ice surface elevation and draft: a case study using coincident AUV sonar and 
638 airborne scanning laser. Journal of Geophysical Research, 116, C00E03.

639 https://doi:10.1029/2011JC00707

640 Fer, I. (2014). Near-Inertial Mixing in the Central Arctic Ocean. Journal of Physical

641 Oceanography, 44(8), 2031-2049. https://doi.org/10.1175/JPO-D-13-0133.1

642 Garbrecht, T., Lüpkes, C., Augstein, E., \& Wamser, C. (1999). Influence of a sea ice

643 ridge on low-level airflow. Journal of Geophysical Research, 104(D20), 24499-24507.

644 https://doi.org/10.1029/1999JD90048

645 Garbrecht, T., Lüpkes, C., Hartmann, J., \& Wolff, M. (2002). Atmospheric drag

646 coefficients over sea ice-validation of a parameterisation concept. Tellus A: Dynamic

647 Meteorology and Oceanography, 205-219.

648 https://doi.org/10.3402/tellusa.v54i2.12129

649 Haapala, J. (2005). A numerical study of open water formation in sea ice. Journal of

650 Geophysical Research, 110(C9). https://doi.org/10.1029/2003JC002200

651 Hanssen-Bauer, I., \& Gjessing, Y. T. (1988). Observations and model calculations of 652 aerodynamic drag on sea ice in the Fram Strait. Tellus A, 40, 161-161. https://doi.org/ $653 \quad 10.1111 / j .1600-0870.1988 . t b 00413 . x$

654 Hinze, J. O. (1975). Turbulence. McGraw-Hill Book, $2^{\text {nd }}$ ed., New York.

655 Hoerner, S. F. (1965). Fluid-Dynamic Drag. Theoretical, experimental and statistical 656 information. 5-7, 2-4 pp., Copyright by: SF Hoerner Fluid Dynamics, Vancouver, 
658 Hunke, E. C., Lipscomb, W. H., Turner, A. K., Jeffery, N., \& Elliott, S. (2013), CICE:

659 The Los Alamos Sea Ice Model Documentation and Software User's Manual Version 660 5.0, Tech. Rep. LA-CC-06-012, Los Alamos National Laboratory, Los Alamos, N. M.

661 Itkin, P., Spreen, G., Cheng, B., Doble, M., Girard-Ardhuin, F., Haapala, J., Hughes, N., 662 Kaleschke, L., Nicolaus, M. \& Wilkinsonet, J. (2017). Thin ice and storms: Sea ice 663 deformation from buoy arrays deployed during N-ICE2015. Journal of Geophysical 664 Research: Oceans, 122(6), 4661-4674. https://doi.org/10.1002/2016JC012403

665 Karim, M., Prasad, B., \& Rahman, N. (2014). Numerical simulation of free surface 666 water wave for the flow around naca 0015 hydrofoil using the volume of fluid (vof) 667 method. Ocean Engineering, 78(mar.1), 89-94.

668 Kharitonov, V. V. \& Borodkin, V. A. (2020). On the results of studying ice ridges in the 669 Shokal'skogo strait, part I: Morphology and physical parameters in-situ. Cold Regions 670 Science $\quad$ and Technology, 103041. 671 https://doi.org/10.1016/j.coldregions.2020.103041

672 Kreyscher, M., Harder, M., Lemke, P., \& Flato, G. M. (2000). Results of the Sea Ice 673 Model Intercomparison Project: Evaluation of sea ice rheology schemes for use in 674 climate simulations. Journal of Geophysical Research: Oceans, 105(C5), 11299-11320. 675 https://doi.org/10.1029/1999JC000016

676 Kwok, R., Cunningham, G. F., Wensnahan, M., Rigor, I., Zwally, H. J., \& Yi, D. (2009). 677 Thinning and volume loss of the Arctic Ocean sea ice cover: 2003-2008. Journal of 
678 Geophysical Research, 114(C7). https://doi.org/10.1029/2009JC005312

679 Launder, B. \& Spalding, D. B. (1972). Lectures in Mathematical Models of Turbulence. 680 Academic Press, London.

681 Leppäranta, M. (2011). The drift of sea ice. 63, 174, 187-189, 159-160 pp., Springer, $6822^{\text {nd }} e d$. , Berlin.

683 Leppäranta, M., Lensu, M., Kosloff, P., \& B Veitch (1995) The life story of a first-year 684 sea ice ridge. Cold Regions Science and Technology, 23, 279-290.

685 Liu, Y., Zhao, Y. P., Dong, G. H., Guan, C. T., Cui, Y., \& Xu, T. J. (2013). A study of 686 the flow field characteristics around star-shaped artificial reefs. Journal of Fluids \& 687 Structures, 39, 27-40. https://doi.org/10.1016/j.jfluidstructs.2013.02.018

688 Lu, P., Li, Z., Cheng, B., \& Leppäranta, M. (2011). A parameterization of the ice-ocean 689 drag coefficient. Journal of Geophysical Research, 116, C07019. 690 https://doi.org/10.1029/2010JC006878

691 Lüpkes, C., \& Birnbaum, G. (2005). Surface Drag in the Arctic Marginal Sea-ice Zone: 692 A comparison of different parameterization concepts. Boundary-Layer Meteorology, 693 117(2), 179-211. https://doi.org/10.1007/s10546-005-1445-8

694 Lüpkes, C., \& Gryanik, V. M. (2015). A stability-dependent parametrization of transfer 695 coefficients for momentum and heat over polar sea ice to be used in climate models. 696 Journal of Geophysical Research: Atmospheres, 120(2), 552-581. 697 https://doi.org/10.1002/2014JD022418 
698 Lüpkes, C., Gryanik, V. M., Hartmann, J., \& Andreas, E. L. (2012). A parametrization, 699 based on sea ice morphology, of the neutral atmospheric drag coefficients for weather 700 prediction and climate models. Journal of Geophysical Research, 117, D13112. 701 https://doi.org/10.1029/2012JD017630

702 Mai, S., Wamser, C. \& Kottmeier, C. (1996). Geometric and aerodynamic roughness of 703 sea ice. Boundary-Layer Meteorology, 77, 233-248. 704 https://doi.org/10.1007/BF00123526

705 Mårtensson, S., Meier, H. E. M., Pemberton, P., \& Haapala, J. (2012). Ridged sea ice 706 characteristics in the Arctic from a coupled multicategory sea ice model. Journal of 707 Geophysical Research, 117(C8). https://doi.org/10.1029/2010JC006936

708 Martin, T., Tsamados, M., Schroeder, D., \& Feltham, D. L. (2016). The impact of 709 variable sea ice roughness on changes in Arctic Ocean surface stress: A model study.

710 Journal of Geophysical Research: Oceans, 121(3), 1931-1952.

711 https://doi.org/10.1002/2015JC011186

712 McPhee, M. G., \& Smith, J. D. (1976). Measurements of the turbulent boundary layer 713 under pack ice. Journal of Physical Oceanography, 6(5), 696-711.

714 McPhee, M. G. (1979). The Effect of the Oceanic Boundary Layer on the Mean Drift 715 of Pack Ice: Application of a Simple Model. Journal of Physical Oceanography, 9(2), 716 388-400. https://doi.org/10.1175/1520-0485(1979)009<0388:TEOTOB >2.0.CO;2

717 Mcphee, M. G. (1994). On the Turbulent Mixing Length in the Oceanic Boundary Layer. 
718 Journal of Physical Oceanography, 24(9), 2014-2031. https://doi.org/10.1175/1520719 0485(1994)024<2014:OTTMLI $>2.0 . \mathrm{CO} ; 2$

720 McPhee, M. G. (2002). Turbulent stress at the ice/ocean interface and bottom surface

721 hydraulic roughness during the SHEBA drift. Journal of Geophysical Research, 722 107(C10), SHE-11. https://doi.org/10.1029/2000JC000633

723 McPhee, M. G. (2008). Air-Ice-Ocean Interaction. Springer, New York.

724 McPhee, M. G. (2012). Advances in understanding ice-ocean stress during and since 725 AIDJEX. Cold Regions Science and Technology, 76-77, 24-36. 726 https://doi.org/10.1016/j.coldregions.2011.05.001

727 Notz, D., \& Stroeve, J. (2018). The Trajectory Towards a Seasonally Ice-Free Arctic 728 Ocean. Current Climate Change Reports, 4(4), 407-416. 729 https://doi:.org/10.1007/s40641-018-0113-2

730 Obert, K. M., \& Brown, T. G. (2011). Ice ridge keel characteristics and distribution in 731 the Northumberland Strait. Cold Regions Science and Technology, 66(2-3), 53-64. 732 https://doi.org/10.1016/j.coldregions.2011.01.004

733 Obukhov, A. M. (1971). Turbulence in an atmosphere with a non-uniform temperature. 734 Boundary-Layer Meteorology, 2, 7-29. https://doi.org/10.1007/BF00718085

735 Onarheim, I. H., Eldevik, T., Smedsrud, L. H., \& Stroeve, J. C. (2018). Seasonal and 736 regional manifestation of Arctic Sea ice loss. Journal of Climate, 31(12), 4917-4932. https://doi.org/10.1175/JCLI-D-17-0427.1. 
738 Orszag, S. A., Yakhot, V., Flannery, W. S., Boysan, F., Choudhury, D., Maruzewski, J.

$739 \&$ Patel, B. (1993). Renormalization group modeling and turbulence simulations.

740 International Conference on Near-Wall Turbulent Flows, 1031-1046.

741 Overland, J. E. (1985) Atmospheric boundary layer structure and drag coefficients over

742 sea ice. Journal of Geophysical Research, 90(C5), 9029-9049.

743 https://doi.org/10.1029/JC090iC05p09029

744 Peralta-Ferriz, C. , \& Woodgate, R. A. (2015). Seasonal and interannual variability of

745 pan-arctic surface mixed layer properties from 1979 to 2012 from hydrographic data,

746 and the dominance of stratification for multiyear mixed layer depth shoaling. Progress

747 in Oceanography, 134(May), 19-53. https://doi.org/10.1016/j.pocean.2014.12.005

748 Petty, A. A., Tsamados, M. C., \& Kurtz., N. T. (2017). Atmospheric form drag

749 coefficients over Arctic sea ice using remotely sensed ice topography data, spring 2009-

750 2015. Journal of Geophysical Research: Earth Surface, 122(8), 1472-1490.

751 https://doi.org/10.1002/2017JF004209

752 Pite, H. D., Topham, D. R., \& van Hardenberg, B. J. (1995). Laboratory measurements

753 of the drag force on a family of two-dimensional ice keel models in a two-layer flow.

754 Journal of Physical Oceanography, 25(12), 3008-3031. https://doi.org/10.1175/1520-

$755 \quad 0485(1995) 025<3008: \mathrm{LMOTDF}>2.0 . \mathrm{CO} ; 2$.

756 Rampal, P., Weiss, J., \& Marsan, D. (2009). Positive trend in the mean speed and

757 deformation rate of arctic sea ice, 1979-2007. Journal of Geophysical Research Oceans, 
758

759

760

761

762

763

Geophysical

Research

Letters,

$26(23)$

114(C5). https://doi.org/10.1029/2008JC005066

764 https://doi.org/10.1029/1999GL010863

765 Sand, B., Bonath, V., Sudom, D. \& Petrich, C. (2015). Three Years of Measurements of

766 First Year Ridges in the Barents Sea and Fram Strait. Paper presented at 23rd

767 International Conference on Port and Ocean Engineering under Arctic conditions,

768 Trondheim, Noway.

769 Schlichting, H., \& Gersten, K. (2017). Boundary-layer theory. 11 pp., Springer, Berlin.

770 Screen, J. A., \& Simmonds, I. (2010). The central role of diminishing sea ice in recent

771 arctic temperature amplification. Nature, 464(7293), 1334-1337.

772 https://doi.org/10.1038/nature09051

773 Shaw, W. J., Stanton, T. P., McPhee, M. G., \& Kikuchi, T. (2008). Estimates of surface

774 roughness length in heterogeneous under-ice boundary layers. Journal of Geophysical

775 Research, 113(C8). https://doi.org/10.1029/2007JC004550

776 Shu, Q., Ma, H., \& Qiao, F. (2012). Observation and simulation of a floe drift near the

777 North Pole. Ocean Dynamics, 62(8), 1195-1200. https://doi.org/10.1007/s10236-012- 
778

779

780

781 https://doi.org/10.1029/2011GL048970

782 Steele, M., Morison, J. H., \& Untersteiner, N. (1989). The partition of air-ice-ocean

783 momentum exchange as a function of ice concentration, floe size, and draft. Journal of 784 785 https://doi.org/10.1029/JC087iC08p05845

795 Timco, G. W., \& Burden, R. P. (1997). An analysis of the shapes of sea ice ridges. Cold 796 Regions Science and Technology, 25(1), 65-77. https://doi.org/10.1016/S0165-
Geophysical

Research:

Oceans,

94(C9),

12739-12750.
Stroeve, J. C., Serreze, M. C., Holland, M. M., Kay, J. E., Malanik, J., \& Barrett, A. P. (2012). The Arctic's rapidly shrinking sea ice cover: a research synthesis. Climatic Change, 110(3-4), 1005-1027. https://doi.org/10.1007/s10584-011-0101-1

Strub-Klein, L., \& Sudom, D. (2012). A comprehensive analysis of the morphology of first-year sea ice ridges. Cold Regions Science and Technology, 82, 94-109. https://doi.org/10.1016/j.coldregions.2012.05.014

Thorndike, A. S., \& Colony, R. (1982). Sea ice motion in response to geostrophic winds. Journal of Geophysical Research: Oceans, 87(C8), 5845-5852. 
798 Tsamados, M., Feltham, D. L., Schroeder, D., Flocco, D., Farrell, S. L., Kurtz, N., et al. 799 (2014). Impact of variable atmospheric and oceanic form drag on simulations of Arctic 800 sea ice. Journal of Physical Oceanography, 44(5), 1329-1353. 801 https://doi.org/10.1175/JPO-D-13-0215.1

802 Wadhams, P., Hughes, N., \& Rodrigues, J. (2011). Arctic sea ice thickness 803 characteristics in winter 2004 and 2007 from submarine sonar transects. Journal of 804 Geophysical Research, 116. https://doi.org/doi: 10.1029/2011JC006982

805 Yakhot, V., \& Orszag, S. A. (1986). Renormalization group analysis of turbulence. i. 806 basic theory. Journal of Scientific Computing, 1(1), 3-51.

807 Zhang, J., Schweiger, A., Steele, M., \& Stern, H. (2015). Sea ice floe size distribution 808 in the marginal ice zone: Theory and numerical experiments. Journal of Geophysical 809 Research: Oceans, 120(5), 3484-3498. https://doi.org/10.1002/2015JC010770

810 Zu, Y., Lu, P., Yu, M., Cao, X., \& Li, Z. (2020). Laboratory experimental study of water 811 drag force exerted on ridge keel. Advances in Polar Science, 31(1): 36-42. 812 https://doi.org/10.13679/j.advps.2019.0026 


\section{QAGUPUBLICATIONS}

Journal of Geophysical Research: Oceans

Supporting Information for

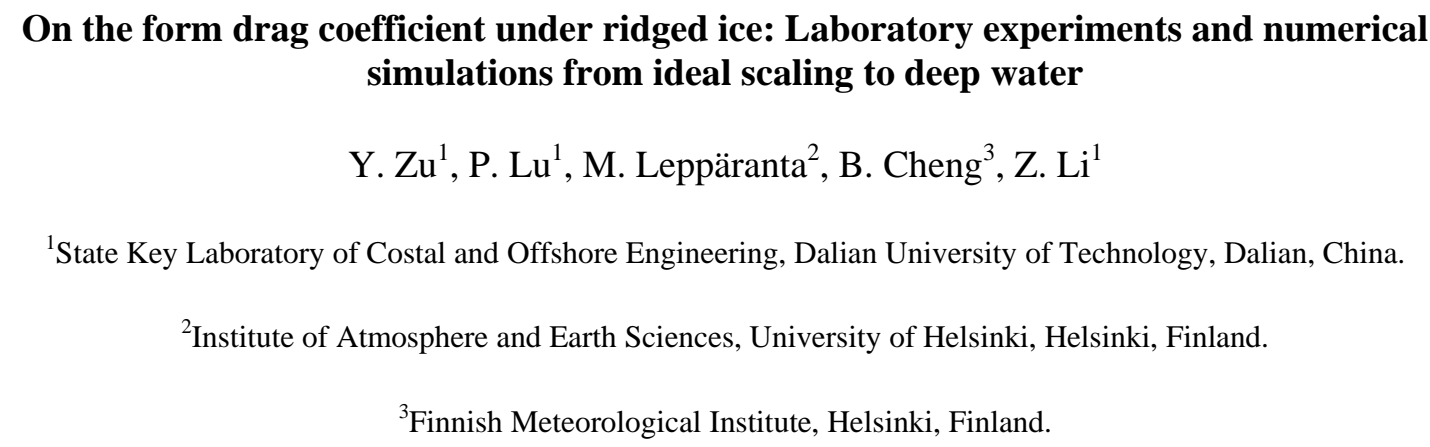
simulations from ideal scaling to deep water
Contents of this file
Text S1
Figure $\mathrm{S} 1$

\section{Text S1. The difference in parameterization schemes between LU2011 and TS2014}

\section{Introduction}

There are three factors in the difference between the two parameterization schemes, LU2011 and TS2014.

- the reference velocity;

- the sheltering function;

- the dimension assumption;

Text S1 considers the impact of these differences and compares definitions of the local drag coefficient of an individual keel $C_{\mathrm{dw}}$ between two schemes.

\section{The reference velocity}

Two schemes are based on the physical process of ice drift. The formule in schemes are derived from the quadratic drag law for a single floe or keel and their distribution per unit area. The first difference between Tsamados et al. (2014) and Lu et al. (2011) is the expression of quadratic drag law.

TS2014 defines the integral

$$
F=\frac{1}{2} C_{d w z} \rho \int_{z_{01}}^{h_{w}} U(z)^{2} d z
$$


where $U(z)$ is depth-dependent upstream velocity under ice, $z_{01}$ is the hydraulic roughness length of smooth ice, $C_{\mathrm{dwz}}$ is the local drag coefficient at reference depth $z$, since total drag coefficient $\underline{\underline{W}}_{\mathrm{w}}$ in TS2014 is defined as,

where $\tau$ is the form drag per unit horizontal area, $U(10)$ is the fluid velocity relative at $10 \mathrm{~m}$ depth. Due to the difference in velocity, there is some difference in the local drag coefficient $C_{\mathrm{dw}}$ between the two schemes. TS2014 uses the law-of-the-wall to assume the upstream velocity profiles. The velocity profile is described by the law of the wall,

$$
U(z)=u_{*} / \kappa \ln \left(z / z_{01}\right)
$$

where $u_{* 1}$ is the friction velocity under the smooth ice, $\kappa$ is the von Kármán constant, and $z_{01}$ is roughness length of the smooth ice. The formula of $U(\mathrm{z})$ is used in the Eq. (S.1).

LU2011 adopts the far-field velocity in the term $U^{2} h_{\mathrm{w}}$. The relationship can be expressed as

$$
F=\frac{1}{2} C_{d w} \rho_{w} U^{2} h_{w}
$$

where $F$ is the force on the frontal area of a keel or floe per unit length, $C_{\mathrm{dw}}$ is the local drag coefficient, $U$ is the velocity at reference depth, and $h_{\mathrm{w}}$ is keel or floe depth. In this study, we also use the far-field velocity to calculate the local drag coefficient.

In real condition, far-field velocity is ice speed relative to geostrophic current. There is a similarity structure in the ice-ocean boundary layer (IOBL), but it is more complex than the ideal turbulent plate boundary layer due to the Ekman layer in which the famous spiral structure exists (McPhee, 2008). Shaw et al. (2008) and McPhee (2012) suggested the IOBL fluid dynamic similarity to address several factors that affect the ice-ocean drag relationship, including ice velocity relative to geostrophic velocity. According to the Rossby similarity (Blackadar and Tennekes, 1968) and the law of the wall, the final expression of dimensionless form considers velocity rotating in the IOBL,

$$
\frac{U}{u_{*}}=\frac{1}{\kappa}\left[\ln \left(\frac{u_{*}}{f z_{0}}\right)-A_{i} \mp i B_{i}\right]=\frac{1}{\kappa}\left[\ln \left(R o_{*}\right)-A_{i} \mp i B_{i}\right\rfloor
$$

where $f$ is the Coriolis parameter, $R o^{*}=u * / z_{0}$ is the surface friction Rossby number, and $\mp i B_{i}$ is the imaginary component depending on the hemisphere (- north). Parameters $A_{i}$ and $B_{i}$ are empirical values to be determined from stress statistics and velocity measurements or calculated from dimensionless depth-invariant eddy viscosity. According to the statistic by McPhee $(1979 ; 1994 ; 2008$, Ch. 9) and Shaw et al. (2008), $A_{i}=2.2 \pm 0.2, B_{i}=2.2 \pm 0.1$ are constants for neutral condition. The effect of Coriolis force is evident in the velocity direction, however, the velocity value varies little with the Coriolis force, i.e., the value of real part of dimensionless velocity in Eq. (S.5) is 15.4 and the absolute value is $16.3\left(u_{*}=0.031 \mathrm{~m} / \mathrm{s}, z_{0}=0.05 \mathrm{~m}\right.$, the selection basis of the parameters will be explained later). In our study, the analysis only considers the absolute value of the icewater stress assuming that the water current below the frictional boundary layer is zero.

For the same ice velocity $U, u_{*}$ and $z_{0}$ should obey the relationship as Eq. (S.5). McPhee (2012) has found that the dimensionless velocity $U / u *$ tends to stable with the increase of $U$ at constant $z_{0}$. In the case, we select two typical roughness length values of $z_{0}$ and $z_{01}$ respectively representing rough ice (including pressure keels) and smooth ice. According to the relevant study by McPhee (2002) and Shaw et al. (2008), $z_{0}=0.05 \mathrm{~m}$ and 
$z_{01}=0.001 \mathrm{~m}$ are used in the calculation. When $U=0.1-0.5 \mathrm{~m} / \mathrm{s}$, we obtain that $u *=0.008$ $0.031 \mathrm{~m} / \mathrm{s}$ and $u_{* 1}=0.005-0.020 \mathrm{~m} / \mathrm{s}$ according to Eq. (S.5). Combined Eqs. (S.4) and (S.5),

78 we get

where $S$ is sheltering function, $A$ is ice concentration, $h_{\mathrm{w}}$ is keel depth, and $L_{\mathrm{r}}$ is keel spacing. $C_{\mathrm{rw}}$ at $10 \mathrm{~m}$ reference depth in TS2014 is as follow,

If LU2011 adopts the Eq. (S.2), the total drag coefficient of keels at 10m reference depth is obtained,

According to the law-of-the-wall (Eq. S.3) used in TS2014, the integration in Eq. (S.1) can be written as follow,

$$
\int_{z_{01}}^{h_{w}} U(z)^{2} d z=h_{w} \frac{u_{* 1}^{2}}{\kappa^{2}}\left(\ln \left(\frac{h_{w}}{z_{01}}\right)\right)^{2} .
$$

90

$$
C_{r w}=f_{2}^{L U} C_{d w}=\frac{1}{\pi} C_{d w} \frac{U^{2}}{U(10)^{2}} \frac{A h_{w}}{L_{r}} S^{2},
$$

$$
C_{r w}=f_{2}^{T S} C_{d w z}=\frac{1}{2} C_{d w z} \frac{A h_{w}}{L_{r}} \frac{U\left(h_{w}\right)^{2}}{U(10)^{2}} S^{2},
$$

where the parameters are same as that in Eq. (S.9). Combined with Eqs. (S.1, S.6, S.8, S.9 and S.10), the relationship between $C_{\mathrm{dw}}$ and $C_{\mathrm{dwz}}$ is got as follow,

$$
C_{d w z}=C_{d w} \frac{U^{2}}{U\left(h_{w}\right)^{2}} \frac{2}{\pi}=C_{d w} \frac{u_{*}^{2} \Phi\left(R O_{*}\right)}{u_{* 1}^{2}\left(\ln \left(\frac{h_{w}}{z_{01}}\right)\right)^{2}} \frac{2}{\pi}=C_{d w} C_{\mathrm{h}} \frac{2}{\pi}
$$

where $C_{\mathrm{h}}$ is the conversion coefficient between $C_{\mathrm{dwz}}$ at keel depth and $C_{\mathrm{dw}}$. Note that the term of $\left(\ln \left(h_{\mathrm{w}} / z_{01}\right)\right)^{2}$ in $C_{\mathrm{h}}$ varies little with $h_{\mathrm{w}}$ and $z_{01}$ (Tsamodas et al., 2014). With parameters analyzed in above text $\left(z_{0}=0.05 \mathrm{~m}, u_{*}=0.020 \mathrm{~m} / \mathrm{s} ; z_{01}=0.001 \mathrm{~m}, u_{* 1}=0.013 \mathrm{~m} / \mathrm{s}\right)$, $C_{\mathrm{h}}=1.1-1.3$ corresponding with $h_{\mathrm{w}}=5-10 \mathrm{~m}\left(C_{\mathrm{h}}\right.$ increases with the decrease of $\left.h_{\mathrm{w}}\right)$. Note that the relationship between $u_{*}$ and $z_{0}$ under ice in this study is still simplified by ignoring the effect of keel depth $h_{\mathrm{w}}$ on $z_{0}$, and further studies are needed. The factor of $2 / \pi$ will be discussed later.

The comparison between TS2014 and LU2011 is made in the oceanic environment. TS2014 is designed for that, and we take our lab result for the keel form drag and use it for a real sea ice ridge. Eqs. (S.1) and (S.4) hold true whether there is Coriolis present or not, but implicitly the Coriolis effect must be in the background when we take the lab results to the oceanic environment for the reference depth at the bottom of the Ekman layer. Then, Eq. (S.6) shows the ice velocity comes from Rossby Similarity Theory when $u *$ and $z_{0}$ are known. Using a non-rotational model for $U$ would not be realistic in ocean environment. As a whole, taking our lab experiment to nature, it is clear that Coriolis comes into the picture and Eq. (S.6) is a proper formula for $U^{2} h_{\mathrm{w}}$.

\section{The sheltering function}

$S$ in Eqs. (S.9-S.10) is the sheltering function and its form is different in the two schemes. LU2011 adopted the quadratic attenuation function by Steele et al. (1989), whereas TS2014 adopted the exponential attenuation function by Hassen-Bauer and Gjessing (1988). The details are beyond the scope of this paper. 


\section{The dimension assumption}

In addition to these two factors $\left(C_{\mathrm{dw}}\right.$ at reference velocity and the sheltering function), there is another difference between the two schemes: the dimension assumption. TS2014 accounts for keel orientation in both the orientation distribution function and the mean ridging density in 2D domain, while LU2011 only accounts for it in the orientation distribution function in 1D domain. When this parameterization is applied to keels, the constant factor of TS2014 is $\pi / 2$ times the value in LU2011, as shown in Eq. (S.11).

\section{Conclusion}

In general, as shown in Eq. (S.11), the factors of $C_{\mathrm{h}}$ and $2 / \pi$ should be considered when the two schemes are compared. We select the $C_{\mathrm{h}}$ value about 1.2 in our comparison. Then the total factors of $2 C_{\mathrm{h}} / \pi$ is about 0.76 , in other words, $C_{\mathrm{dw}}$ in LU2011 should multiply 0.76 compared with $C_{\mathrm{dwz}}$ in TS2014.

\section{Figure S1}

134 As in Fig. 5 in the main article, Fig. S1 shows a series of velocity profiles along the 135 horizontal direction when $D / h_{\mathrm{w}}=14$.
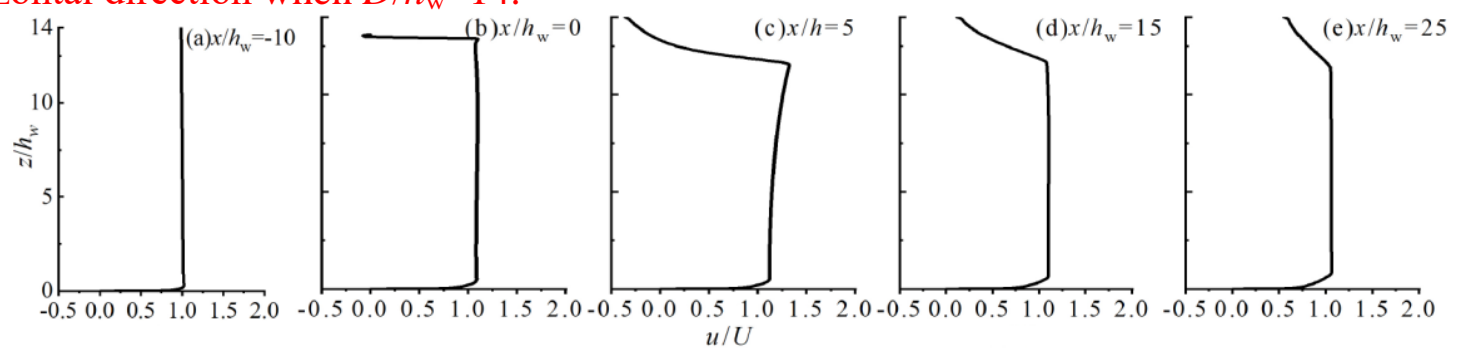

Figure S1. A series of velocity profiles along the horizontal direction, with $\alpha_{\mathrm{w}}=45^{\circ}$, $D / h_{\mathrm{w}}=14$ and $U=0.3 \mathrm{~m} / \mathrm{s}$. (a) $\mathrm{x} / h_{\mathrm{w}}=-10$, (b) $\mathrm{x} / h_{\mathrm{w}}=0$, (c) $\mathrm{x} / h_{\mathrm{w}}=5$, (d) $\mathrm{x} / h_{\mathrm{w}}=15$, (e) $\mathrm{x} / h_{\mathrm{w}}$ $=25$. 